\title{
Investigaciones en el ushnu mayor de Incahuasi, Cañete: contribuciones al estudio de los ushnus incas
}

\section{Research in the main Incahuasi ushnu, Cañete: contributions to the study of Inca ushnus}

\author{
Alejandro Chu* \\ University of Pittsburgh \\ Department of Anthropology
}

\section{Resumen}

El sitio arqueológico de Incahuasi, ubicado en el valle medio de Cañete de la costa surcentral peruana, ha sido mencionado reiteradamente en la literatura arqueológica; sin embargo, los estudios efectuados en el asentamiento han tenido hasta la fecha un carácter superficial. Recientes investigaciones realizadas en el sector $\mathrm{E}$ han permitido conocer la complejidad constructiva del ushnu de la plaza principal del sitio y se ha llegado a identificar, al menos, tres fases constructivas asociadas a cambios de tamaño y orientación. Las excavaciones del ushnu mayor constituyen un ejemplo de la compleja ocupación del sitio, desarrollada por un tiempo mucho mayor al que mencionan los documentos coloniales.

Director del Proyecto Arqueológico Incahuasi, Cañete.

Correo electrónico: alejandrochu@gmail.com 
Palabras clave: ushnu, arquitectura inca, Tawantinsuyu, arqueología de Cañete, Incahuasi

\begin{abstract}
The archaeological site of Incahuasi, located in the middle valley of the Cañete river, in the south-central coast of Peru, has often been mentioned in the archaeological literature; however, studies in the settlement have been superficial to date. Recent research conducted in sector $\mathrm{E}$ have shown the constructive complexity of the ushnu in the main square of the site and at least three construction phases associated with changes in size and orientation have been identified. Excavations of the main ushnu show the complex occupation of the site, which was developed during a much longer time than those mentioned in colonial documents.
\end{abstract}

Keywords: ushnu, Inca architecture, Tawantinsuyu, Cañete archaeology, Incahuasi

$$
* * *
$$

\title{
Introducción
}

12 La arquitectura representa una de las expresiones culturales más características de los incas y resalta por su monumentalidad y planeamiento. A medida que el Tawantinsuyu iba expandiéndose, los incas construyeron grandes centros administrativos que fueron puntos clave en el control y manejo del territorio. La existencia de estos asentamientos planificados fuera del área nuclear del Cusco refleja el alto grado de organización que el imperio había desarrollado en los terri- 
torios conquistados en un lapso no mayor de ochenta años, antes de ser invadido por los españoles en 1532.

Es en los centros administrativos incas donde se aprecia el planeamiento arquitectónico y el empleo de una serie de elementos que remarcan la presencia del Estado; entre estos elementos arquitectónicos destacan dos importantes espacios: el ushnu y la plaza. Las plazas y las estructuras asociadas a ellas corresponden generalmente al área nuclear de los asentamientos, donde irradiaban los caminos y se concentraban las estructuras más notables. El ushnu, una de las principales estructuras localizadas en las plazas de las llaqtas incas, jugó un importante rol ceremonial.

En este artículo se presentan los trabajos de excavación efectuados en el ushnu mayor del sitio arqueológico de Incahuasi, asentamiento inca construido en condiciones particulares, pues de haber sido inicialmente una base de operaciones durante la guerra contra los guarcos, se transformó posteriormente en un centro administrativo provincial estratégicamente localizado en la chaupiyunga del valle de Cañete.

\section{Estudios sobre ushnus}

Las referencias sobre estas estructuras se pueden encontrar en cronistas tempranos como Sancho de la Hoz (1968 [1534]: 332) y Ruiz de Arce (1968 [1545]: 432), quienes describen posibles ushnus sin emplear este término. De acuerdo con Tom Zuidema (1980: 412), Molina, Albornoz y un anónimo fueron los primeros cronistas en introducir la palabra ushnu en sus descripciones sobre el Cusco inca. En el Lexicón de Domingo de Santo Tomás aparece el vocablo ozño u osño (Santo Tomás 1951 [1560]) registrado como ushñu o ushño en la edición crítica publicada en 2013, con la definición de: altar para o donde se sacrifica (Santo Tomás 2013 [1560]: 783). 
Cronistas más tardíos como Guamán Poma (1980 ([15831615]: 239, 357) los identifican como un trono del inca o un lugar para los sacrificios humanos qhapaq bucha (1980 [15831615]: 236). Para una completa recopilación del término ushnu en documentos coloniales se recomienda consultar a Pino Matos (2010), quien hace una revisión de 31 fuentes documentales coloniales.

Los ushnus excavados han sido muy pocos y las publicaciones donde se reportan estos trabajos son menos aún. Hay estudios y descripciones detalladas de ushnus de los sitios de Huánuco Pampa (Morris y Thompson 1985: 58-59) y Pumpu (Matos 1994: 214-221) en la sierra central; Usnu Moq'o (Oberti 1997: 15-21) en Abancay; Ushnu Pata, Inka Pirqa, y Ushnu Pirqa en Ayacucho (Meddens y otros 2008: 327-340); Maucallacta en Arequipa (Presbítero y otros 2000-2001; Wołoszyn y otros 2010); Shincal de Quimivil (Raffino y otros 1997: 23-37; Lynch y otros 2013: 102-105) y Hualfin Inka (Lynch y otros 2013: 100-102) en el noroeste argentino.

Sin embargo, son abundantes los estudios referentes al uso e importancia de los ushnus dentro de la sociedad inca; en ellos se los caracteriza como importantes espacios para el culto y las ofrendas con una correlación astronómica. Entre los primeros investigadores interesados en esta temática tenemos a Tom Zuidema (1989 [1980]), quien en su artículo El Ushnu destaca la importancia astronómica de estas estructuras como centros de observación de las puestas del sol en los meses de 14 agosto y abril, fechas que marcaban, respectivamente, el inicio y el término de las labores agrícolas.

John Hyslop (1990) se pregunta, ¿qué es un ushnu?: "El concepto de ushnu es complejo y variado. Sirvieron como tronos o altares (Gasparini y Margolies 1980: 264-280). No solo fueron plataformas simples, sino también piedras que incorporaban el concepto de pila con un sistema de drenaje" (1990: 69; la traducción es mía). 
Recientemente, destacan los estudios de José Luis Pino (2004, 2005 y 2010) en relación con los ushnus del Chinchaysuyo y los de Rodolfo Monteverde $(2007,2010)$ que comparan los ushnus conocidos hasta la fecha y la conexión que estos tuvieron con el culto inca y su rol como espacio de libaciones.

Con la literatura disponible, queda clara la importancia de los ushnus dentro del aparato ceremonial inca; es este rol ritual el que motiva que sean identificados frecuentemente en el registro arqueológico asociado a las plazas de los asentamientos imperiales. Los elementos arquitectónicos que conforman un ushnu son una poza o pila, canales y tianas o asientos; usualmente, estos componentes se localizan sobre plataformas a las que se accede por escalinatas o rampas. Dependiendo del tamaño e importancia del asentamiento y su ubicación, encontramos ushnus con todos o algunos de estos elementos.

\section{Incahuasi, el "Nuevo Cuzco"}

\section{Ubicación}

El sitio arqueológico de Incahuasi se encuentra ubicado en el valle medio de Cañete, en una quebrada seca conocida como San Andrés o Incahuasi. Este sector del valle forma parte de la jurisdicción del anexo de Paullo, distrito de Lunahuaná, provincia de Cañete, región Lima (figura 1); su ubicación a 350 m.s.n.m., lo sitúa al inicio del valle medio o chaupiyunga, caracterizada por estar encajonada entre cerros desérticos de pendiente pronunciada. La zona irrigada del valle, correspondiente a sus márgenes y fondo, presenta un ancho de medio a un kilómetro. Trece kilómetros río abajo, en dirección suroeste, se llega a la planicie costera constituida por un delta de casi 20 kilómetros de ancho donde el río Cañete desemboca en el océano Pacífico. 
Investigaciones en el ushnu mayor de Incahuasi, Cañete ...

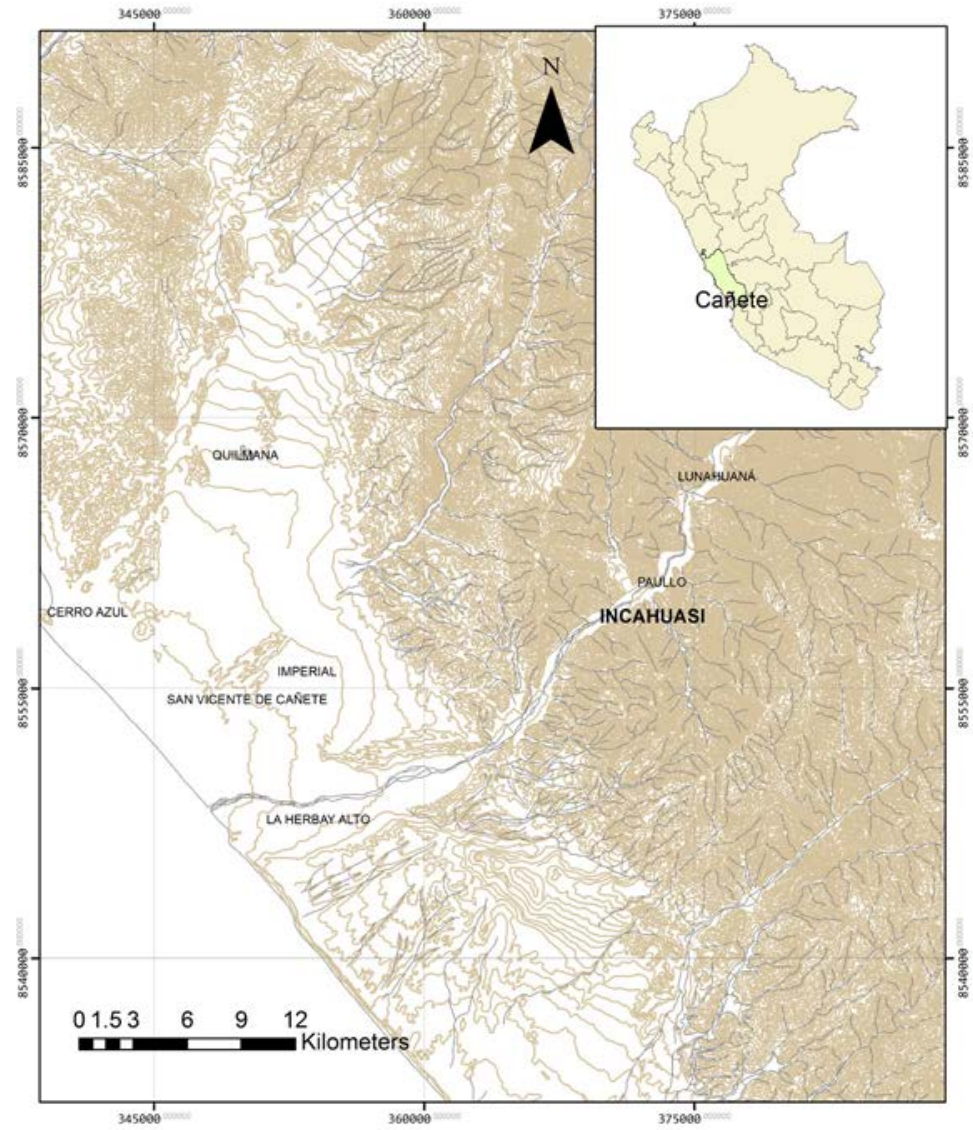

Figura 1

Antecedentes históricos

La primera mención sobre Incahuasi y su importante papel en la campaña inca contra los guarcos fue registrada por Pedro Cieza de León en 1553; encontramos referencias sobre este episodio tanto en la primera como en la segunda parte 
de su Crónica del Perú (capítulos 73 y 60, respectivamente). Se considera que dicha obra estaría basada en información confiable obtenida de primera mano (Hyslop 1985: 8).

Otras fuentes históricas únicamente dan pequeñas referencias sobre Guarco e Incahuasi. Para Cabello de Valboa (1951 [1586]), el nombre guarco, que significa "peso" o "pesa", se impuso en el valle después de la conquista inca, cuando los rebeldes vencidos fueron colgados de las murallas de su fortaleza. Las crónicas de Acosta y Cobo (citadas en Rostworowski 1978-80: 156) narran que la conquista del valle de Cañete se logró con un ataque sorpresa durante una celebración religiosa relacionada con la pesca. Garcilaso de la Vega, por su parte, dedica un par de páginas en su crónica a la conquista de Guarco, pero al parecer mucha de su información fue tomada de la crónica de Cieza. Este último menciona en la primera parte de su Crónica del Perú:

Y que como los Ingas viniessen conquistando y haziéndose señores de todo lo que vían: no queriendo estos naturales quedar por sus vassallos (...) sostuvieron la guerra, y la mantuuieron con no menos ánimo que virtud más tiempo de quatro años (...) Y como la porfía durasse, no embargante que el Inga se retiraua los veranos al Cuzco por causa del calor, sus gentes tractaron la guerra: que por ser larga, y el rey Inga auer tomado voluntad de la llegar al cabo: abaxando con la nobleza del Cuzco edificó otra nueva ciudad, a la cual nombró Cuzco, como a su principal assiento. Y quentan assimismo, que mandó que los barrios y collados tuuiessen los nombre propios que tenían los del Cuzco (Cieza 1995 [1553]: 215).

Y complementa esta información en la segunda parte de su crónica:

Topa Inga revolvió sobre el Cuzco y como los hombres de acá sean de tan poca cosntancia, como vieron que los guarco se quedaron con lo que intentaron, comenzo a ver 
novedaes entre algunos de ellos y se revelaron alguno y se apartaron del serviçio del Inga (...) Y como llegase al princiio del valle de Guarco, en las haldas de una sierra de aquellos çecedades, mandó a sus jentes a fundar una ciudad a la cual puso por nombre Cuzco como a su principal asiente y las calles y collados y plaças tuvieron nombre de las verdaderas. Dixo que hasta Guarco sea ganado y los naturales sujetos suyos, avia de permanecer en la nueva población y que en ella siempre avia de aver jente de guarniçion (Cieza 1996 [1553]: 174).

Finalmente, en la misma crónica, Cieza narra cual fue el fin de aquel "Nuevo Cuzco":

Asentado el Valle [el Inca] y puesto mitimaes y gobernador, aviendo oydo las embazadas que le vinieron de los yungas y de muchos serranos mandó ruynar el nuevo Cuzco que se avia hecho y con toda su jente dio la vuelta para la ciudad del Cuzco donde fue recibido con gran alegría y se hicieron grandes sacreficios con alabança suya en el tenplo y oráculos [...] (Cieza 1996 [1553]: 175).

Como ha señalado John Hyslop (1985: 12), Cieza visitó el valle bajo de Cañete, aunque no es claro si llegó a visitar Incahuasi. Los datos que presenta son sin embargo tan útiles, que permitieron a Hyslop llegar a ciertas conclusiones consideradas actualmente la base para el desarrollo de futuras investigaciones arqueológicas en Incahuasi:

1. El Inca Tupac Yupanqui (Topa Inca) construyó una ciudad identificada como un "Nuevo Cuzco" o "Cuzco" en el valle medio de Cañete, actualmente denominada Incahuasi, que fue la base de operaciones en su campaña militar contra los guarco, campaña que duró de 3 a 4 años.

2. La ciudad fue construida replicando a la ciudad del Cusco, capital del imperio, con sus calles y plazas, y renombrando los cerros vecinos con los nombres de las elevaciones que rodean la capital cusqueña. 
3. Cuando los incas ganaron la guerra contra los guarco, el "Nuevo Cuzco" dejó de ser utilizado y fue abandonado; Cieza ([1553]1995: 217) lo menciona claramente: "perdiéndose el nombre de la nueva población que habían hecho". Incluso en la segunda parte de la crónica Cieza dice que Tupac Yupanqui: "mando ruinar el nuevo Cuzco que se habían hecho" (Hyslop 1985: 12; la traducción es nuestra).

\section{Investigaciones previas}

Escuetas descripciones de Incahuasi aparecieron en algunas publicaciones de los siglos XIX y XX, producto de expediciones de viajeros y visitas cortas por parte de algunos arqueólogos. De estas breves referencias podemos destacar las siguientes contribuciones que permitieron aumentar significativamente lo que se conoce del sitio arqueológico.

En 1904, Eugenio Larrabure y Unanue publicó una breve descripción sobre Incahuasi, siendo posteriormente ampliada en su recopilación de obras (Larrabure 1935 [1893]: 419439). Escrito como una crónica de viaje a la zona, el trabajo de Larrabure se concentra en describir el Sector E (denominado Incahuasi), considerado por él como un sitio diferente del resto; se publica, asimismo, el primer plano del sector y fotografías en donde se observa el asentamiento sin ninguna ocupación moderna y en buen estado de conservación. Este texto corresponde a la primera descripción conocida del sector y del sitio arqueológico.

En 1933, el arquitecto Emilio Harth-Terré publicó el artículo "Incahuasi - Ruinas Incaicas del Valle de Lunahuaná" en la Revista del Museo Nacional, con algunos de los primeros planos de varios sectores del sitio, incluido un plano del sector Incahuasi, el cual es muy similar al publicado en 1904 por Larrabure y Unanue. Esta publicación describe aspectos de la arquitectura de varios sectores del sitio y presenta por 
primera vez reconstrucciones hipotéticas de algunas de las estructuras visibles en superficie.

Monseñor Pedro Villar Córdova publicó en 1935 Las culturas prehispánicas del departamento de Lima, en donde se menciona a Incahuasi. Villar Córdova (1935: 269) realizó otra sectorización del sitio y lo dividió en el Palacio del Inca, cuarteles y graneros especiales, ciudad conventual y fortaleza o pucara. Publicó asimismo algunas fotografías del sitio en las que se destaca el buen estado de conservación de las estructuras.

En 1941, los arqueólogos Junius Bird, Julio C. Tello, Duncan Strong y Gordon Willey visitaron brevemente Incahuasi (Strong y Willey 1943: 20) y registraron el sector correspondiente a Cerro Hueco (sectores $\mathrm{G}$ y $\mathrm{H}$ ) como un sitio independiente. Aunque no realizaron investigaciones en el sitio, publicaron algunas fotografías en las que se destaca su buen estado de conservación, a pesar de que ya tenía evidencias de una ocupación moderna: una parte de la plaza mayor era usada como cancha de futbol (Strong y Willey 1943: plate 5b).

Carlos Williams y Francisco Merino publicaron en 1974 el Inventario, catastro y delimitación del patrimonio arqueológico del valle de Cañete en dos tomos. Aunque el sitio recibe el código 27-K 1J06, Williams y Merino otorgan dos nombres al sitio: Incahuasi, que designa a los sectores ubicados en la quebrada principal, y El Arca, referido a las estructuras ubicadas en la pequeña quebrada oeste, conocidas comúnmente como el

20 Acllawasi. En la quebrada principal identificaron 5 sectores. Es interesante que estos investigadores asignen al sector El Arca una ocupación desde el período Intermedio Tardío, lo que se reflejaría en un desarrollo no armónico como en los otros sectores del sitio (Williams y Merino 2008 [1974]: 75). En relación con la ocupación moderna del sitio, Williams y Merino ya advertían a inicio de la década de 1970: “[...] el conjunto de Incahuasi está en un franco proceso de destruc- 
ción, principalmente por el hecho de servir como estación de los pastores trashumantes del área" (Williams y Merino 2008 [1974]: 74).

En 1985, el arqueólogo John Hyslop publicó un estudio a nivel superficial sobre Incahuasi, basado en el trabajo de campo que inició en 1979 y continuó con visitas periódicas al sitio durante 1980, 1982 y 1983 (Hyslop 1985: IX). A partir de su estudio, Hyslop pudo definir 8 sectores en el sitio y, basado en recolecciones sistemáticas de superficie, logró establecer las posibles funciones de los complejos arquitectónicos (figura 2). En el marco de esta investigación se tomaron las primeras fotos aéreas del sitio empleando un globo aerostático; para esa fecha, el sitio se encontraba ocupado permanentemente por chivateros que invadieron todo el asentamiento con sus viviendas y corrales, siendo los principales responsables de su destrucción.

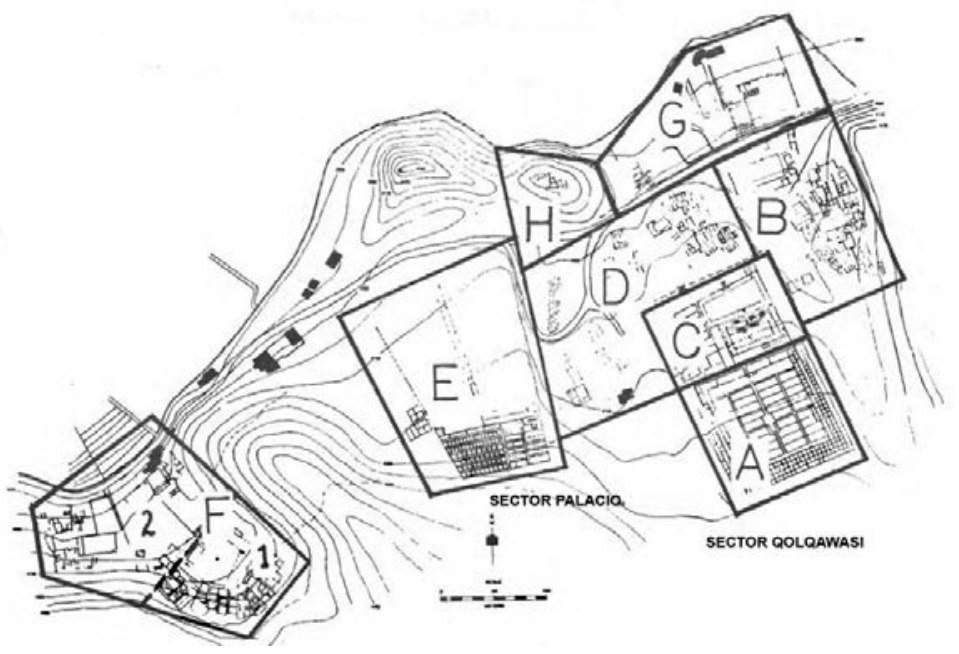

Figura 2 
La arqueóloga Cora Rivas ha publicado recientemente un estudio sobre Incahuasi (Rivas 2011). Al igual que los anteriores trabajos, esta investigación presenta un carácter superficial e incluye un levantamiento topográfico y una nueva propuesta de sectorización del sitio, ligada a una secuencia ocupacional identificada mediante trabajos de prospección.

Por último, a fines del año 2012 se iniciaron las investigaciones arqueológicas del Proyecto Arqueológico Incabuasi, que conllevaron la ejecución de las primeras excavaciones arqueológicas en el sitio concentradas en los sectores $\mathrm{A}, \mathrm{C}$ y E definidos por Hyslop. Se consideró conveniente emplear la sectorización de Hyslop por ser la más precisa, ya que se basa en las características morfo-funcionales de los sectores. El proyecto arqueológico estuvo dirigido a la puesta en valor del sitio, lo que permitió realizar excavaciones en área en los tres sectores, que expusieron casi la totalidad de la arquitectura existente. Se pudo así identificar la extensión de los recintos y sus fases constructivas.

\section{El Sector E}

El ushnu y plaza mayor de Incahuasi se ubican en el Sector $\mathrm{E}$, el que ha sido denominado Incahuasi (Larrabure 1904, 1935 [1893]) o Palacio del Inca (Harth-Terré 1933: 106; Villar Córdova 1982[1935]: 269]). El Sector E se localiza en la

22 parte central del sitio arqueológico y limita al norte con la Zona 2 del asentamiento (el cual fue dividido del sitio por la construcción de la carretera Cañete - Lunahuaná), hacia el este con el Sector C, al sur y al oeste con un promontorio rocoso, en donde, en su otro extremo, se encuentra el Sector F o Acllahuasi. El sector E está compuesto por una estructura principal que corresponde a un gran complejo de planta trapezoidal con un muro perimétrico de 1 metro de ancho y 4 metros de alto denominado Sub-sector 1 y que correspon- 
de al palacio propiamente dicho. Inmediatamente al norte de esta estructura y compartiendo los ejes de su trazado, se ubica la plaza y ushnu mayor correspondientes al Sub-sector 2. En el presente artículo, solo nos concentraremos en las excavaciones realizadas en el ushnu y la porción de plaza alrededor del mismo.

La plaza de forma trapezoidal, definida por Hyslop (1985: 118) como un trapezoide (ya que no hay dos lados paralelos), se extendía por toda la explanada norte de la estructura principal. La posición elevada del sector E, al estar emplazado sobre una planicie ligeramente más alta que los demás sectores, le asegura un amplio dominio visual sobre el valle. La plaza en su extremo norte ha sido muy afectada por el camino Cañete - Lunahuaná y en la década de 1990 una gran porción de ese extremo fue cortada para la construcción de la carretera asfaltada. Por las referencias de Larrabure y Unanue (1904: 3), es muy probable que los lados oeste y este de la plaza estuvieran delimitadas por muros de 240 y 230 metros de largo y 87 centímetros de ancho (figura 3). En la actualidad solo se observan restos de las bases de estos muros. Con los recortes modernos, la plaza cuenta en la actualidad con un área de 14700 metros cuadrados y un perímetro de 489 metros, originalmente estas dimensiones debieron ser mayores. En el eje central de la plaza se tiene una calzada de baja altura (media de 3 centímetros) que culmina en el ushnu.

Una de las más detalladas descripciones, y la más antigua, data de 1904 y se encuentra consignada en la obra de Larrabure y Unanue, quien visitó Incahuasi cuando aún no había experimentado ninguna alteración o destrucción y describe al ushnu como:

Un monumento original: es un cuadrilongo de 1.80 de alto, 3.85 de ancho y 13.30 de largo con sus escaleras de piedra al frente y detrás, coronado por otro más pequeño compuesto de muritos que dejan un hueco el centro, afectando la for- 
ma de cajón ó canal cerrado a sus extremos. De suerte que subiendo cómodamente por una escalera, se podía circular enredor de este curioso monumento y descender por la escalera opuesta, sobre la misma avenida. Estas dos escaleras, idénticas, compuestas de 5 pasos 0.55 ancho y 0.23 alto cada una lado formando pasaje (Larrabure 1904: 4).

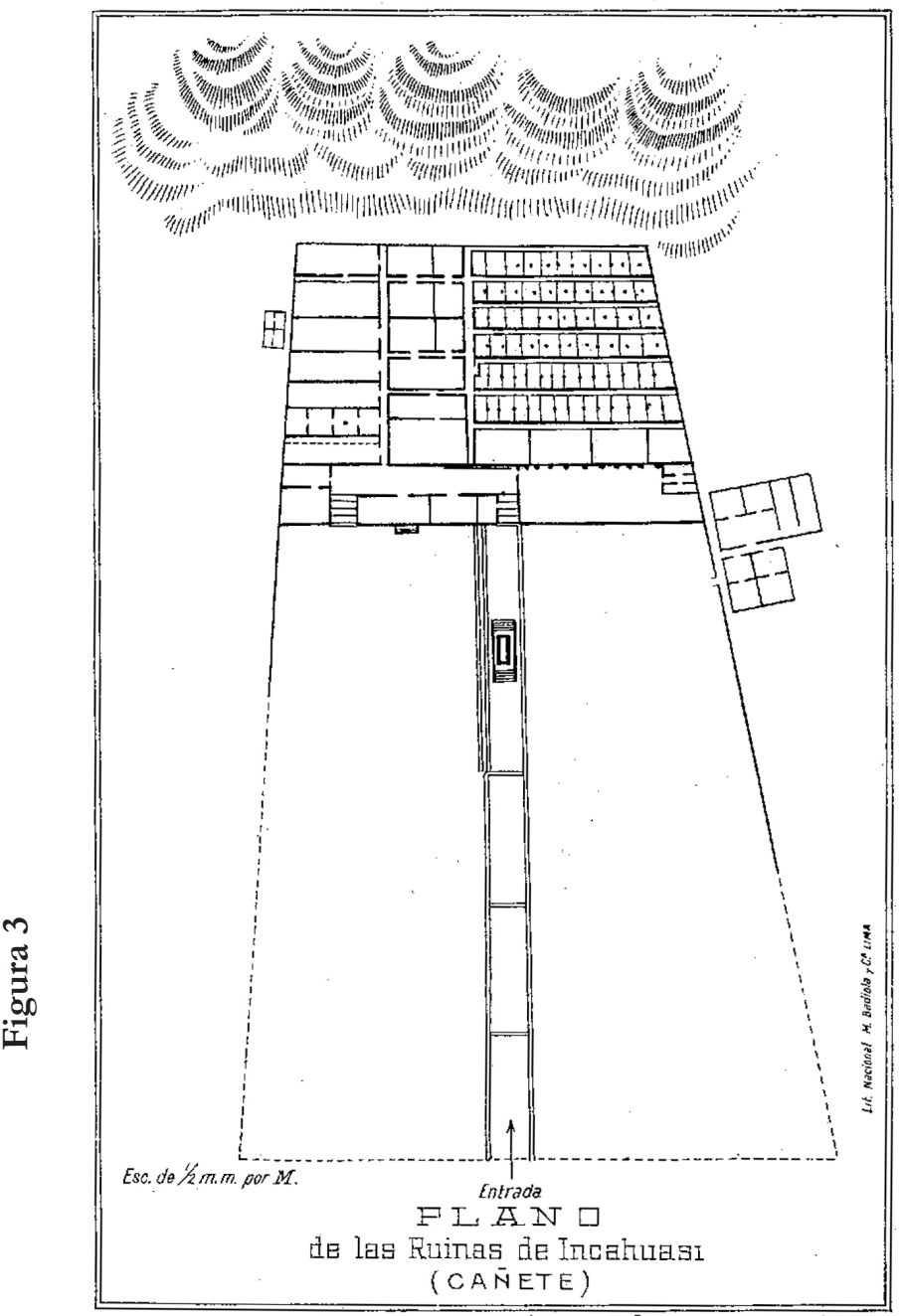


De manera más breve, Harth-Terré describe el ushnu (al que denomina "altar") en su publicación de 1933:

Tiene en su centro un túmulo de piedra y barro sobre el que se halla el altar de los sacrificios, también del mismo material y semejante al del primer patio de Colcahuasi y al de las casa de las acllas. Se accedía a él por la parte anterior y posterior con dos escaleras de lajas de piedra asentadas sobre tierra (Harth-Terre 1933: 107).

Según el criterio de Harth-Terré, el ushnu era un adoratorio en donde se realizaban sacrificios humanos y la quema de hojas de coca a manera de incienso. Se desconoce cómo fue que llegó a esa conclusión.

Tendrían que pasar varias décadas para que encontremos otra descripción del ushnu de Incahuasi. Hyslop lo caracteriza como una plataforma rectangular de adobes sobre el camino. Fotografías publicadas por Strong y Willey (1942: plate 5b) muestran la plataforma en buen estado, casi intacta con escaleras hacia la parte superior (1985: 118, la traducción es mía).

Sin embargo, ni en superficie ni durante la excavación arqueológica se encontraron evidencias de adobes constructivos. El mismo autor menciona que antes de su investigación en el sitio, efectuada en 1979, el ushnu ya había sido destruido; esta afirmación resulta evidente si se comparan las imágenes publicadas por Larrabure y Unanue en 1904, Villar Córdova en 1935 y Strong y Willey en 1943 con las que él presentó en 1985 (Hyslop 1990: 90). Para la época en que Hyslop investigó Incahuasi, el sitio ya había sido invadido por ganado y pobladores; el ushnu y parte de la plaza se habían convertido en un corral de cabras (figura 4).

Posteriormente, un morador de la zona que funge de guardián y guía turístico realizó labores de limpieza, restituyó piedras en las cabeceras de muros y en las esquinas del ushnu, 
y una escalera de acceso en su lado este, dejando al descubierto parte del muro norte de la estructura, que presenta enlucido blanco (figuras 5 a y 5 b).

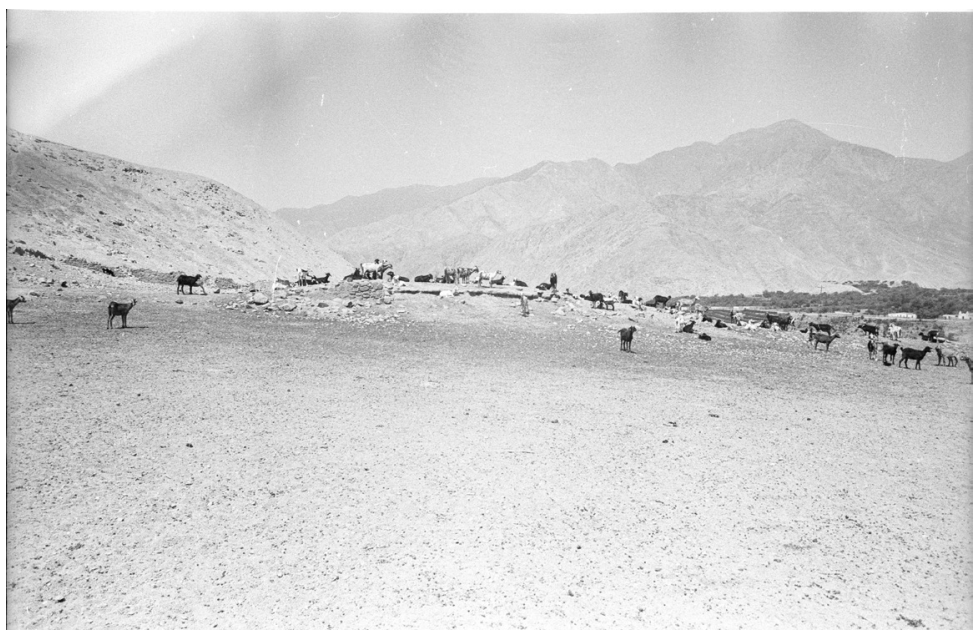

Figura 4

Excavaciones en el ushnu

Antes de iniciar los trabajos de excavación, se efectuó el cuadriculado del área que se iba a excavar. Se emplearon unidades de excavación de 5 por 5 metros las que, a su vez, se dividieron en subunidades de 1 por 1 metro orientadas hacia el norte. Las unidades de excavación se enumeraron consecutivamente con números arábigos. La excavación fue realizada de acuerdo con las unidades de excavación y las subunidades, en caso de que se descubrieran hallazgos o elementos arquitectónicos que requirieran mayor precisión en su registro. Una vez que se pudo definir la arquitectura subyacente, se procedió a continuar las excavaciones empleando unidades arquitectónicas (U.A.) como unidad de 


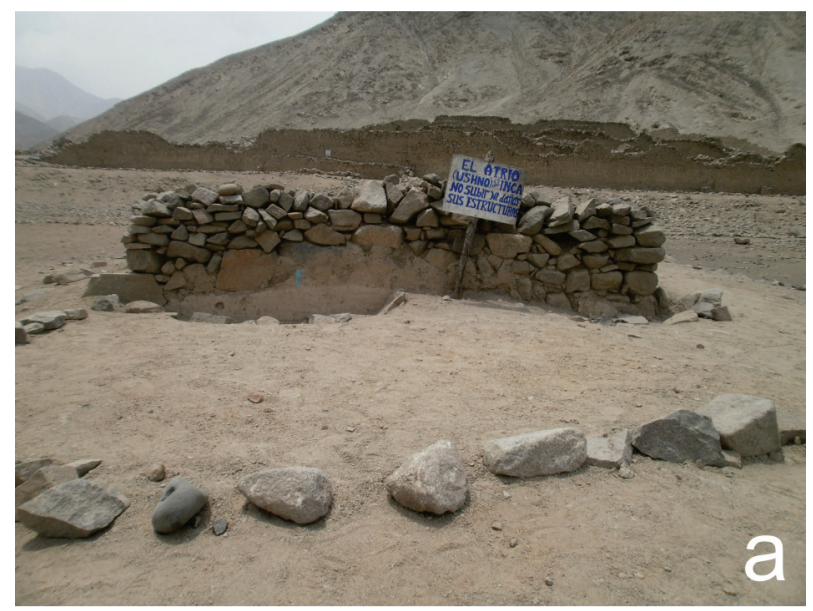

Figura $5 a$

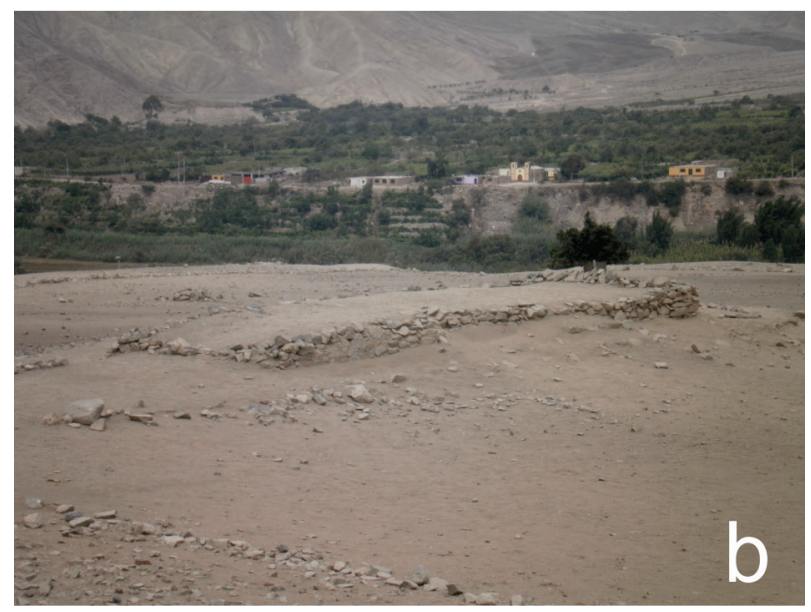

Figura 5b 
registro. Los estratos fueron excavados siguiendo las deposiciones culturales y naturales; todo el proceso de excavación fue registrado tridimensionalmente, gráfica, escrita y fotográficamente.

Los estratos, tanto naturales como culturales, fueron denominados unidades estratigráficas (U.E.). Cada U.E. fue numerada con un número arábigo correlativo antepuesto a la abreviatura U.E. Para una mejor localización de las U.E. se les puede anteponer el número de la unidad de excavación a la U.E. Las capas, elementos y otros contextos identificados recibieron números de U.E. consecutivos. Durante la excavación, se consideró una estratigrafía horizontal (pisos, apisonados, rellenos, etcétera) y otra vertical (muros); en el caso de los muros, estos recibieron una codificación a nivel de sector que fue realizada por el Área de conservación y restauración de estructuras. Se consideró pertinente que los muros recibieran un código único, tanto para las labores de excavación como para las de conservación, a fin de evitar la duplicación de códigos y confusiones. El material excavado, de acuerdo con su composición, fue zarandeado empleando mallas de 2, 4 y 6 milímetros.

Las excavaciones se iniciaron con el retiro de la capa superficial que cubría toda la superficie del ushnu, la que se extendió de manera homogénea con cierta inclinación de sur a norte por toda esta superficie y la plaza aledaña a la estructura (figura 6). Esta U.E. (numerada como 01) se encuentra conformada por tierra fina, arena de grano grueso, gravilla, cascajo, piedras angulosas grandes, medianas y pequeñas, con escasa presencia de guijarros medianos, de consistencia suelta. También se observan restos modernos compuestos por materiales botánicos y escasos coprolitos caprinos, así como algunas piedras medianas en su superficie. No se reportó material cultural arqueológico. 


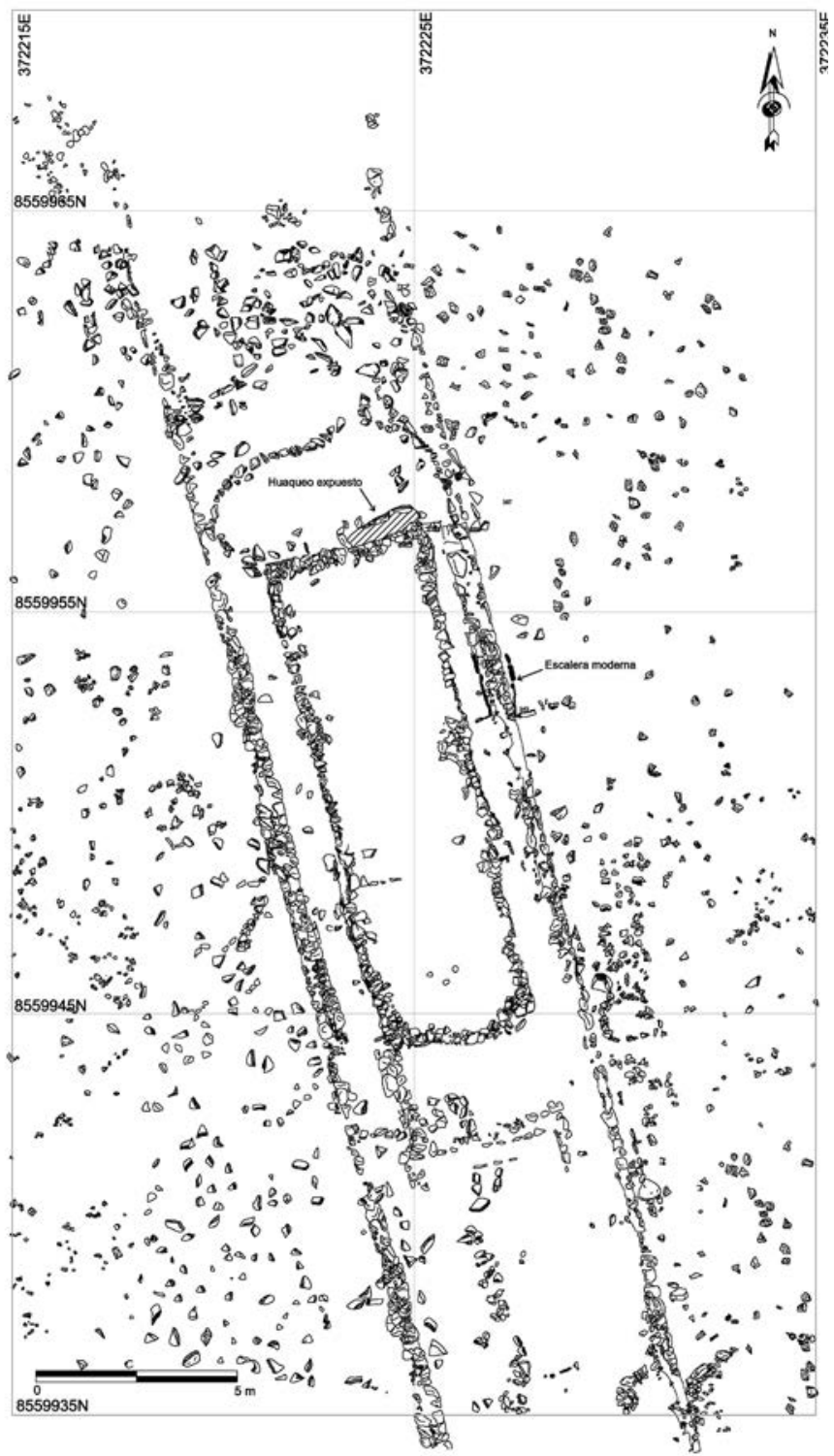

Figura 6 
Inmediatamente debajo de esta capa superficial, se encontraron coprolitos de ganado caprino moderno entremezclados con parte de un relleno constructivo disturbado; los coprolitos estuvieron concentrados en el lado este del ushnu, donde la afectación moderna fue mayor. Dentro del estrato compacto de coprolitos se encontraron algunas piedras angulosas grandes, medianas y pequeñas, escasos cantos rodados medianos y pequeños, cascajo y restos de basura moderna (plásticos, fragmentos de vidrio, clavos y restos botánicos). Esta capa presentó un espesor de entre 22 a 42 centímetros. Al retirar este estrato (U.E. 02), se desmontó una escalinata de acceso al ushnu compuesta por dos peldaños de piedras alargadas, asentadas sobre los coprolitos modernos, su construcción es contemporánea a la actividad ganadera y fue realizada con el fin de que los turistas puedan acceder al ushnu. En el lado este, entremezclado con restos de coprolitos, se define un estrato compuesto por grava, arena gruesa y tierra fina arcillosa. En algunas áreas se observan pequeños fragmentos de mortero. Estos fragmentos presentan restos de enlucido de arcilla y sobre este enlucido, una capa de color blanco; en algunos casos, estos bloques presentan dos o tres caras pintadas, por lo cual cabe suponer que corresponden a las esquinas del muro con enlucido blanco que se aprecia en superficie parcialmente destruido, siendo la grava el relleno constructivo que contenía.

Estos estratos reflejan el proceso de deposición de la ocupación moderna y destrucción del ushnu. Ha sido posible estimar que este proceso duró alrededor de un siglo, ya que durante la excavación se pudo encontrar, entre los diferentes estratos de coprolitos, material moderno diverso que incluyó monedas directamente asociadas a la deposición de coprolitos y rellenos. La moneda más antigua fue encontrada directamente sobre el piso de la plaza, cubierta por coprolito de caprino, y corresponde a un "dinero" de plata del año 1905. Luego se encontraron una moneda de 10 centavos de 1921, otra mone- 
da de 25 centavos de 1968 y una moneda de 100 soles del año 1980, esta última cercana a la superficie (figura 7).

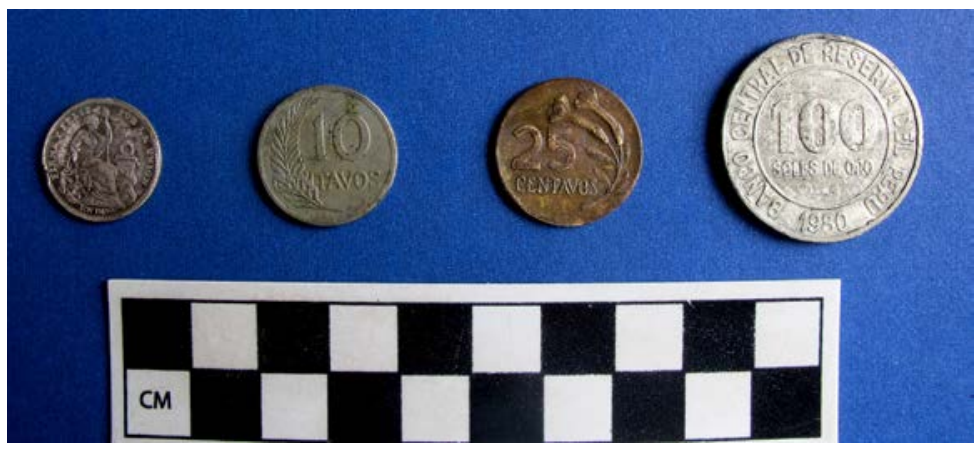

Figura 7

Una vez retirados estos estratos, se pudo definir el ushnu de una manera mucho más clara. Se identificó una plataforma de planta rectangular de 8 por 5 metros, la que presenta muros enlucidos de color blanco en sus lados norte, oeste y sur (muros E2-21, E2-22, E2-24, respectivamente). Estos muros tienen una media de 2 metros de alto y están construidos sobre el piso de la plaza (figura 8). Rodeando al muro blanco se identificó un muro de doble paramento en mal estado de conservación que lo rodea en sus lados norte, oeste y parcialmente en el lado este (muros E2-17, E2-18, E2-19, respectivamente). Este muro corresponde a una ampliación de la plataforma blanca original.

En la parte superior de la plataforma blanca se identificaron los restos de una pila de forma rectangular de $5.2 \times 1.7$ metros, la cual presenta en su interior las improntas de pequeños cantos rodados (figura 9). Tanto la pila como el resto del piso de la plataforma estuvieron pintados de blanco. En el lado oeste de la plataforma se encontró una escalera de 


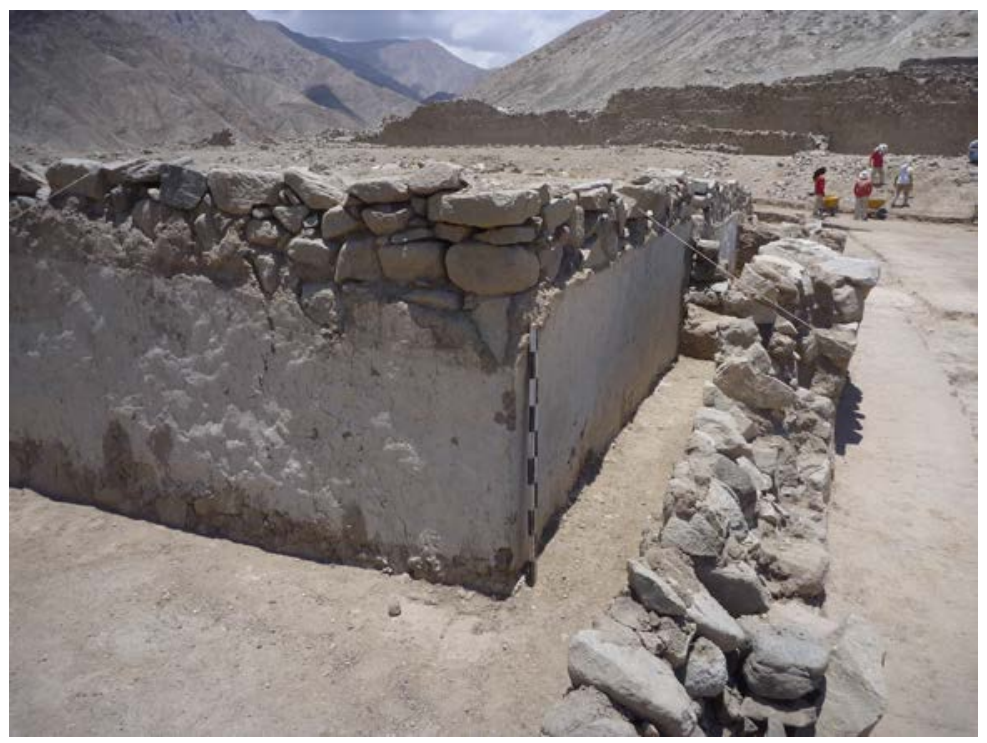

\section{Figura 8}

acceso de 67 centímetros de ancho compuesta por cinco peldaños, la que fue bloqueada por la construcción del segundo muro (muro E2-18) a escasos 50 centímetros de este. El espacio resultante entre estos dos muros fue rellenado con grava y ripio limpio. En el lado este hay un solo muro (E2-23), lo que reflejaría una reutilización del muro de este lado para ambas plataformas. Lamentablemente, es justo este lado del ushnu el que ha sido más afectado por la ocupación ganadera; esta destrucción se extiende por todo el lado este de la parte superior de la plataforma y afecta el lado este de la pila, el piso de la plataforma y el muro (E2-23), que fue desmontado y dejó expuesto el relleno de la plataforma. La exposición de los rellenos permitió comprobar que los muros de la plataforma son de doble paramento y que su relleno está compuesto por grava y arena gruesa limpia sin restos culturales. Durante la excavación de la deposición moderna en 
este lado del ushnu se encontraron pequeños cantos rodados negros y grises oscuros entremezclados con los coprolitos y basura moderna, lo que hace suponer que corresponden a los cantos de la pila que fue destruida durante esa ocupación.

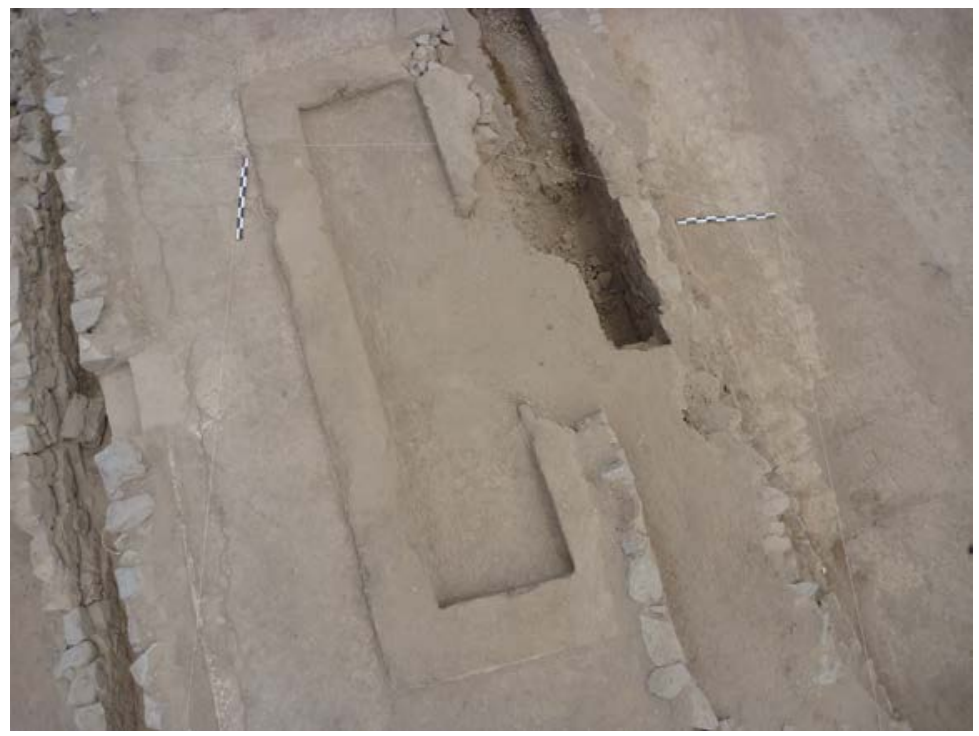

Figura 9

En un segundo momento constructivo, se amplía el tamaño de la plataforma con la construcción de los muros E2-17, E2-18, E2-19, los que definen una plataforma de 12.2 x 6.5 metros (figura 10). Los muros de este segundo momento se construyeron sobre el piso de la plaza y se encuentran en mal estado de conservación, presentan colapsos, pandeos, pérdida de mortero, rajaduras y grietas. Aparentemente, estuvieron expuestos a la intemperie por lo que son los más afectados (en algunas porciones solo se encontró 25 centímetros de alto del muro). En pequeñas áreas se ha podido identificar 
Investigaciones en el ushnu mayor de Incahuasi, Cañete ...

restos de enlucido y pintura roja, lo que hace suponer que esta plataforma estuvo pintada de rojo.

En el lado sur del ushnu se encontró que asociado a este segundo momento se construyó una plataforma de 4 × 3 metros adosada al muro sur de la primera plataforma, que sirvió de acceso a la nueva estructura, ya que en su lado sur se definen dos peldaños (figura 11).
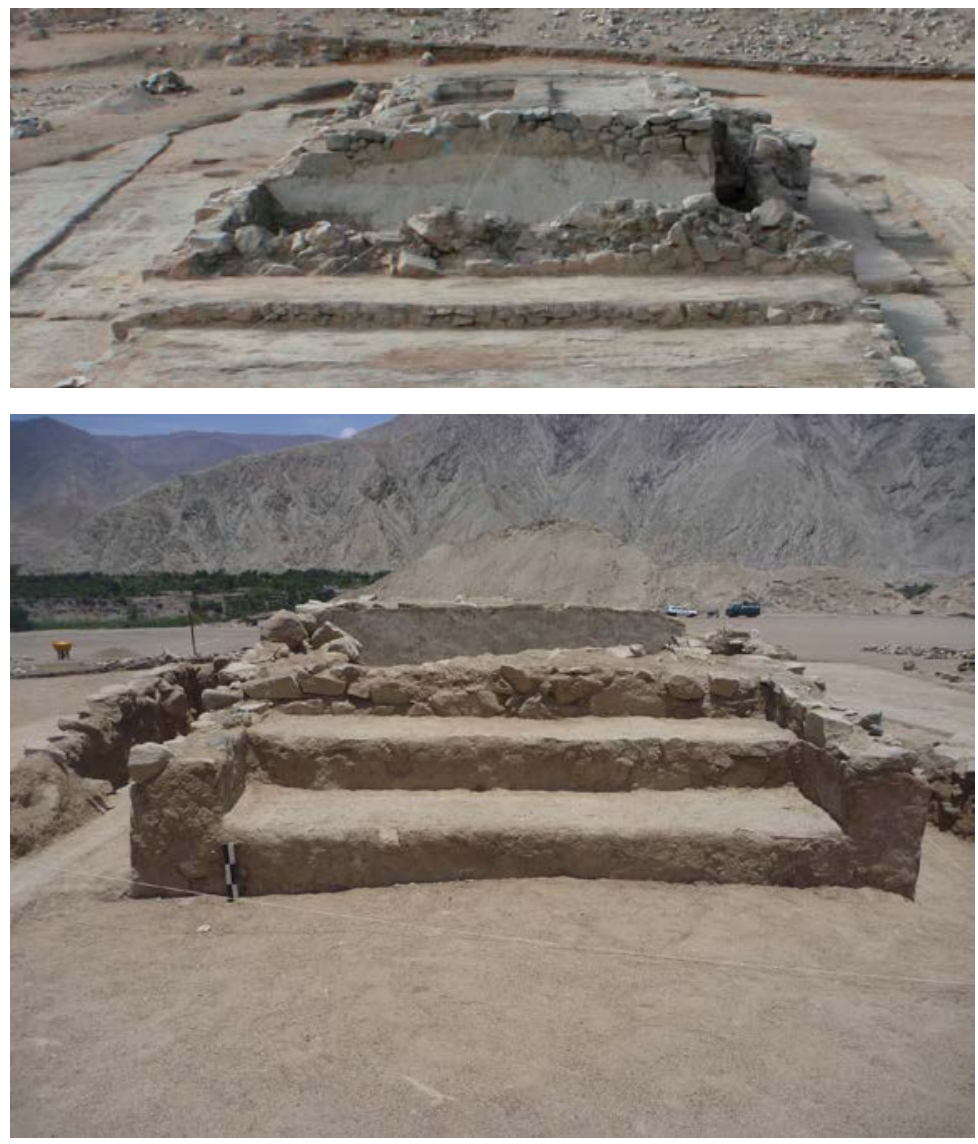

Figuras 10 y 11 
En el lado norte de esta segunda plataforma no se encontraron restos de algún acceso como en el lado sur; sin embargo, las excavaciones permitieron definir que el muro en ese lado (muro E2-17) se había desplomado en bloque (figura 12), lo que permitió restaurarlo y definir que debió tener una altura de más de 2 metros. En los espacios resultantes por la ampliación de la plataforma y la construcción del acceso sur, se rellenó con grava y ripio limpio compactado; no se encontraron restos culturales en estos rellenos.

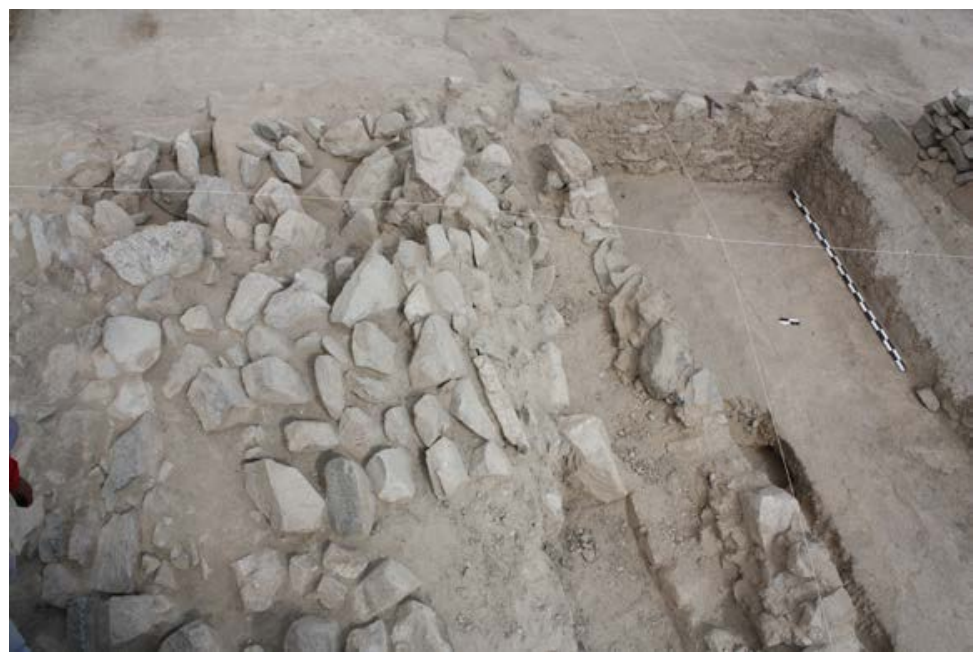

Figura 12

Las excavaciones también permitieron identificar que junto con la construcción del muro norte de la segunda plataforma (muro E2-17) se habían adosado dos plataformas en el lado norte, del mismo ancho que la plataforma (6.5 metros) y orientación, de 2 metros de largo y 70 centímetros de alto la primera, y la segunda de 3 metros de largo y 50 centímetros de ancho. Es en la parte central de esta segunda plataforma 
que se descubrió una pila de 1.80 por 1.00 por 0.5 metros (figura 13 y 14). Esta pila se encontraba cubierta por el relleno del camino, por lo que se encontró en buen estado de conservación con su pintura de color amarillo y su contenido de cantos rodados pequeños. La pila y las plataformas se construyeron sobre el piso de la plaza.

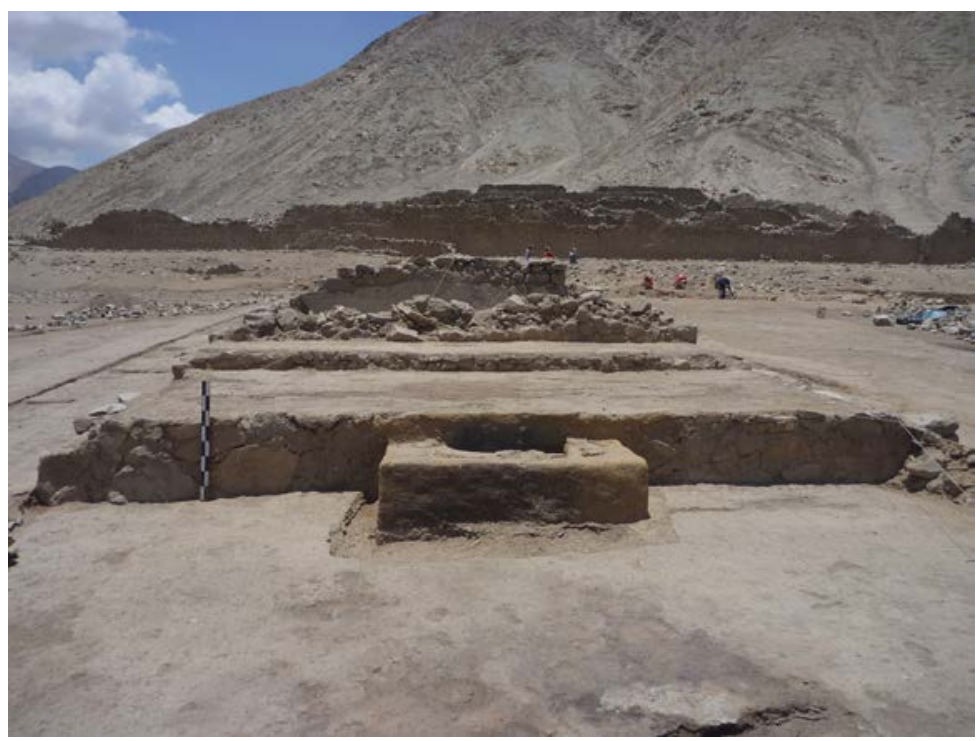

Figura 13

36 Las excavaciones han permitido definir claramente que el camino central de la plaza corresponde a un momento constructivo posterior al ushnu, ya que, como se mencionó líneas arriba, este camino elevado cubre a la pila amarilla con su relleno constructivo. Este relleno difiere de los encontrados en el ushnu, ya que no solo presenta grava y arena gruesa, sino también piedras angulosas de diverso tamaño y material cultural (botánico principalmente) entremezclado o formando lentes. Al retirar los rellenos del camino se descubrió el 


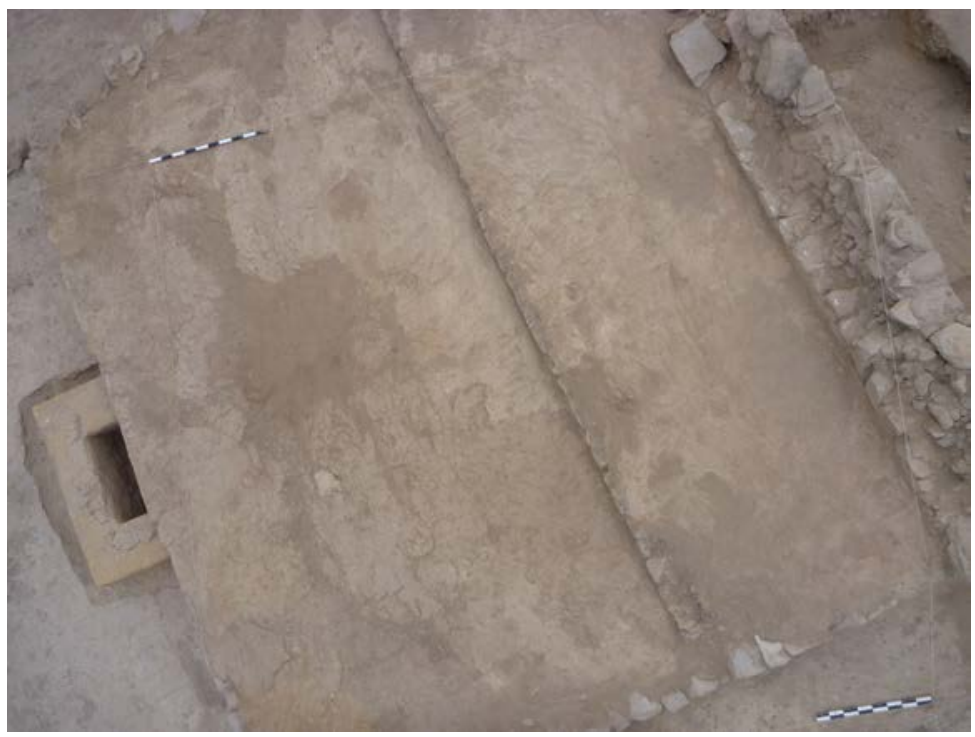

\section{Figura 14}

piso de la plaza. Debido a la presencia de piedras grandes y material cultural, este relleno no es homogéneo ni compacto. Los muros de los lados del camino se adosan a la plataforma del ushnu amarillo.

En la parte sur del ushnu, la construcción del camino se realizó variando ligeramente la construcción de la plataforma, que quedó conectada con el acceso a la estructura principal. Este cambio de orientación se habría motivado por la necesidad de conectar el acceso y el ushnu. Es en este momento constructivo que el ushnu habría dejado de cumplir su función original, por lo se selló la pila amarilla. El relleno de este lado del camino es de similares características que el empleado en el lado norte; en el extremo sureste de este relleno se recuperó una concentración de material cultural que incluía la muestra de cerámica que se presenta líneas abajo. 


\section{Cerámica asociada}

Como se ha mencionado, el material cultural fue muy escaso en las excavaciones del ushnu. Los rellenos constructivos y piso de la estructura se encontraban limpios y sin materiales. En el único lugar donde se encontró una considerable cantidad de material cultural corresponde al lado suroeste del camino elevado, cerca al acceso de la estructura principal, donde el camino elevado se rellenó con material de desecho.

Un análisis de esta material permitió reconocer la presencia de pocos fragmentos diagnósticos, casi la totalidad de manufactura local. Entre los fragmentos diagnósticos se encontraron dos bordes de un plato estilo inca (figura 15). El resto del material presenta formas y decoraciones características del estilo guarco (figuras 16 y 17), tal como fue definido por Joyce Marcus en Cerro Azul (Marcus 2008); se encontraron los tipos Pingüino buff y Camacho marrón rojizo. Otros materiales identificados corresponden a restos de maíz (tallos y tuzas), pacae, guayaba, junco, camarón de río (Cryphios caementarius), chorito (Semimytilus algosus), entre otros.

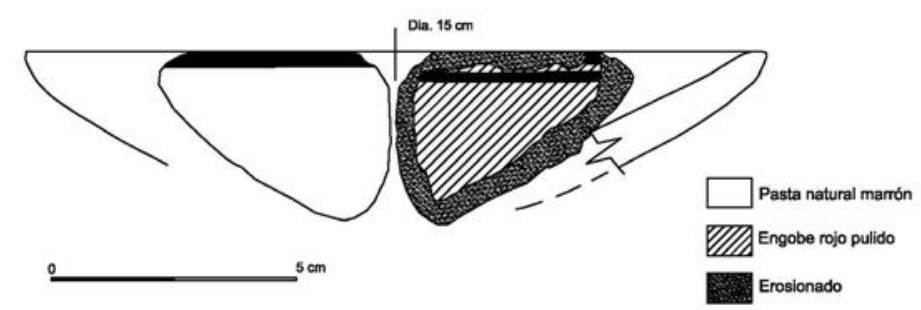

\section{Figura 15}




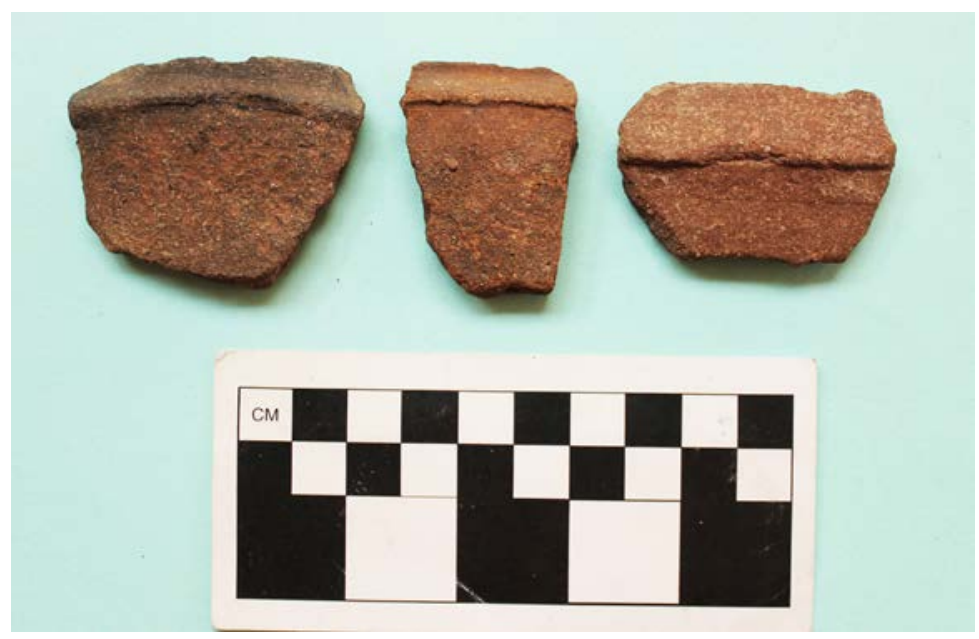

Figura 16

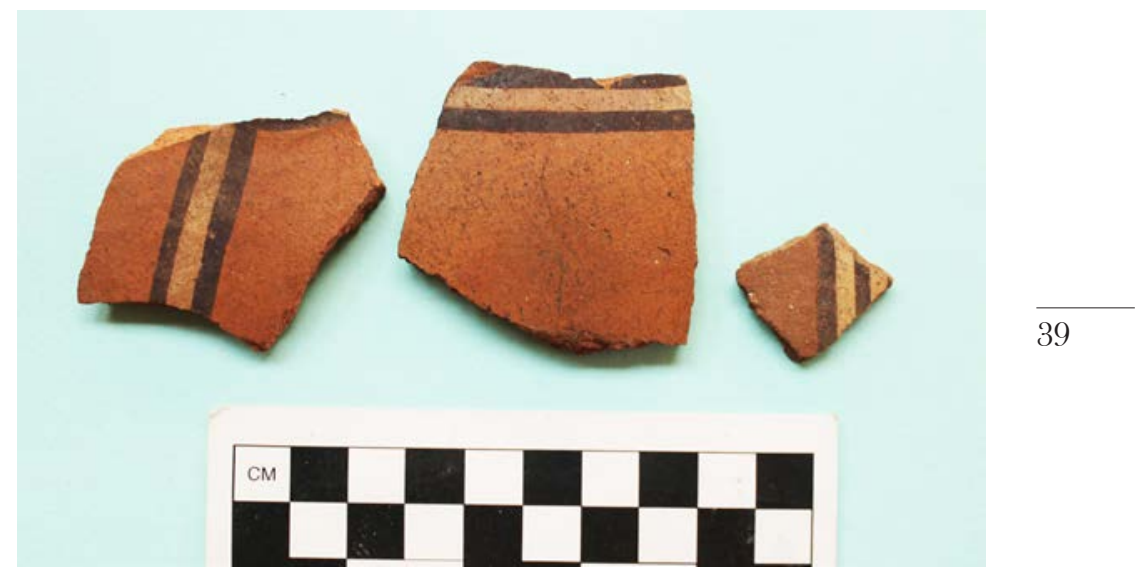

Figura 17 


\section{Excavaciones en la plaza}

Las excavaciones se concentraron alrededor del ushnu y el camino elevado. Al igual que en las excavaciones del ushnu, debajo de la superficie se encontró una densa deposición de coprolitos de ganado vacuno, caprino y ovino, además de cantos rodados pequeños y medianos, y escasa presencia de piedras angulosas grandes y medianas. Se hallaron restos de basura moderna (fragmentos de vidrio, telas, papeles, cigarrillos, entre otros) y restos de quema (ceniza), pero ningún material arqueológico.

Retirado este estrato, se descubrió que el piso de la plaza es de arcilla amarillenta compacta y con una ligera inclinación de sur a norte. La superficie presenta mucho desgaste, así como restos de quema, los que podrían corresponder a la ocupación moderna.

Lo más resaltante de la excavación del piso de la plaza fue el descubrimiento de 4 franjas en alto relieve de un metro de ancho que se extienden paralelamente al ushnu (figuras 18a y 18b). Estas franjas presentan una decoración en bajo relieve de cuadrados de 15 centímetros, los que se encuentran agrupados en dameros de 12 x 4; estos dameros de forma rectangular se ubican a 50 centímetros uno del otro (figura 19).

Estas franjas corren de manera paralela al ushnu y entre cada franja hay 50 centímetros de distancia. Es justo en ese espa-

40 cio que también se ha podido identificar la misma decoración de damero con cuadrados en bajo relieve más pequeños (7 centímetros).

Aparentemente, estas franjas elevadas estuvieron expuestas al igual que el piso de la plaza, ya que presentan mucho desgaste en sus superficies; un fragmento de la franja sur que fue cubierta al construir el camino elevado es el único lugar en buen estado de conservación (figura 20). 


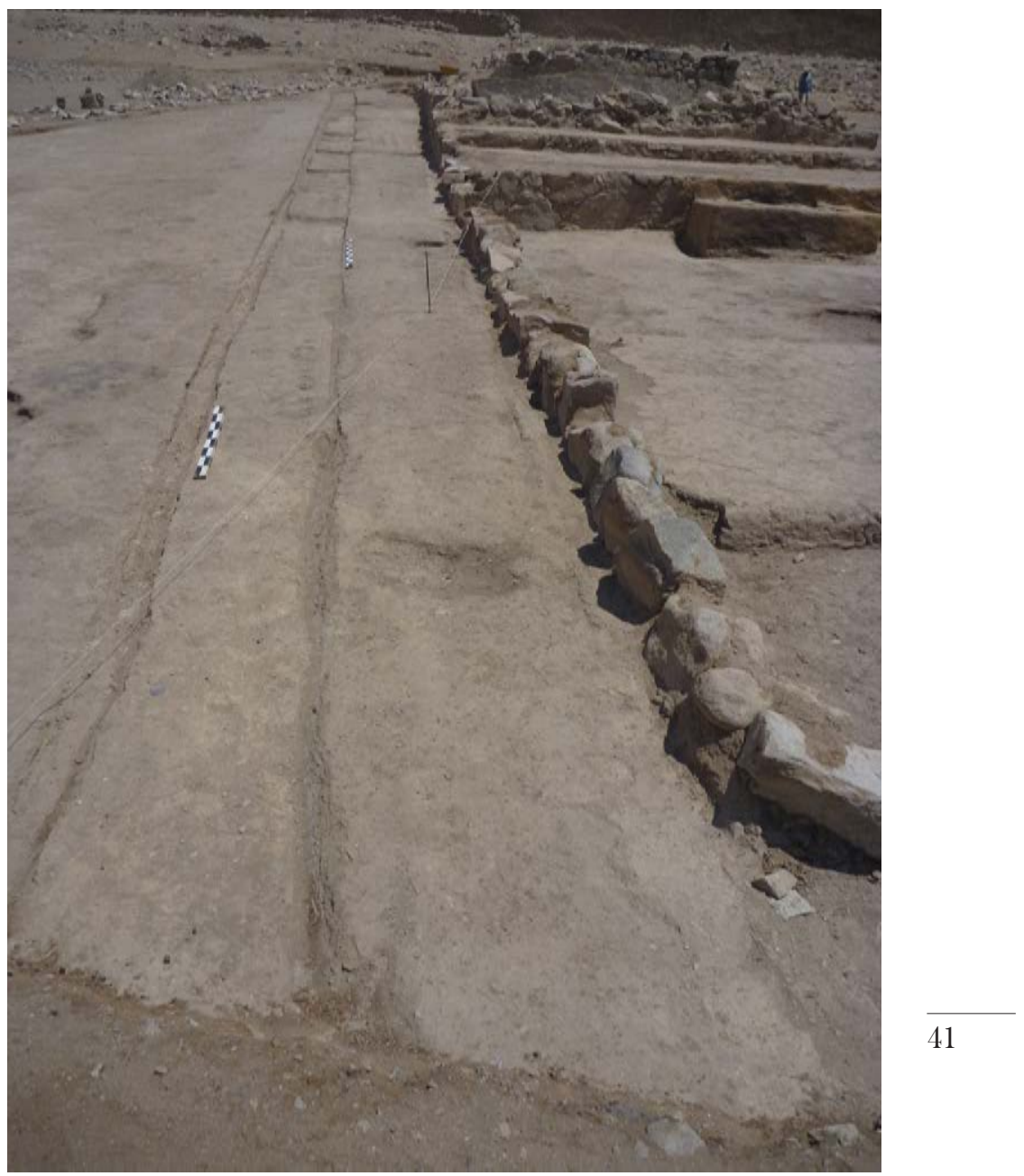

Figura 18a 
Investigaciones en el ushnu mayor de Incahuasi, Cañete ...

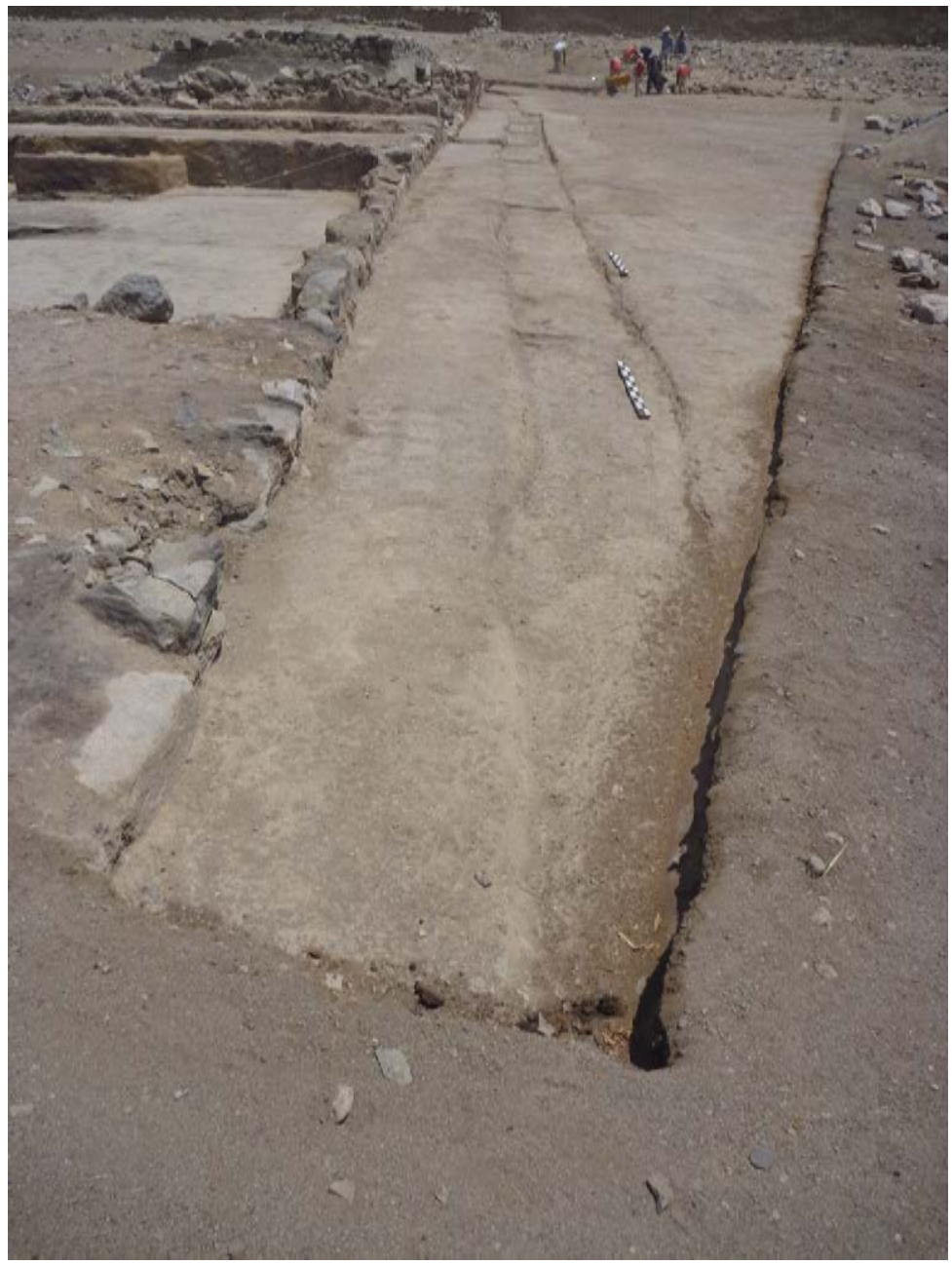

Figura $18 b$ 


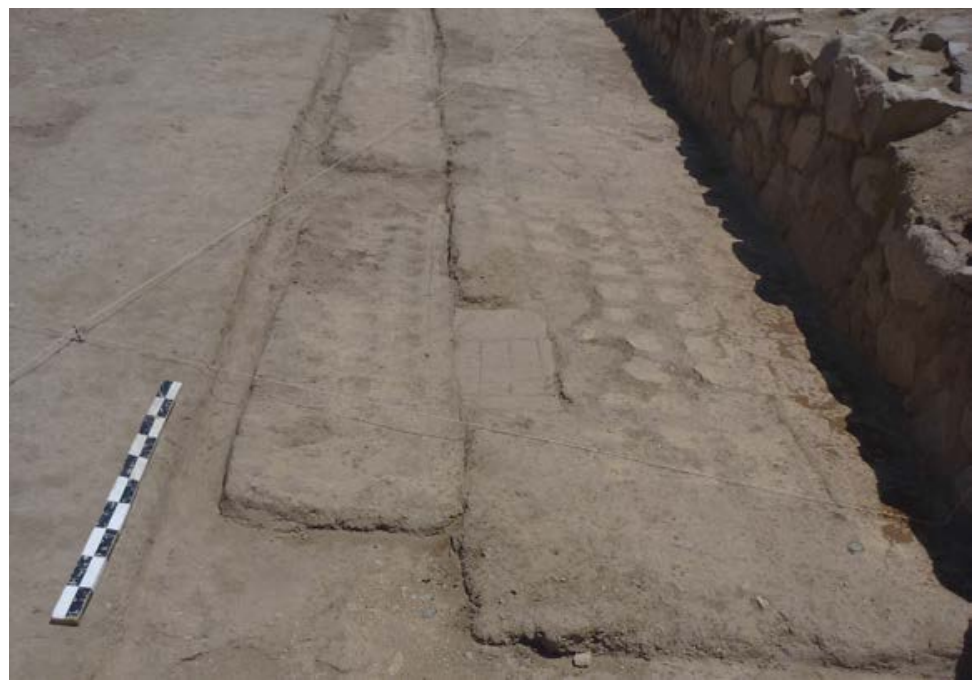

Figura 19

Asociado a los cuadrados en bajo relieve, se ha podido identificar restos de cuadrados incisos (figura 21); lamentablemente, no ha sido podido definir su posición dentro de la secuencia constructiva de la plaza. Los cuadrados incisos habrían sido trazados en damero al igual que los cuadrados en bajo relieve. Son muy similares a los que se han reportado para el Sector C, subsector 1 (Chu, en prensa) y del sector A, subsector 1 (Urton y Chu, en prensa) de Incahuasi.

\section{Conclusiones}

A través de las investigaciones se puede caracterizar al ushnu mayor de Incahuasi como una estructura de carácter ceremonial y compleja secuencia constructiva (figura 22), ya que se realizaron diversas modificaciones asociadas a la función que cumplió. Los datos obtenidos permiten identificar claramente tres fases constructivas: 
Investigaciones en el ushnu mayor de Incahuasi, Cañete ...

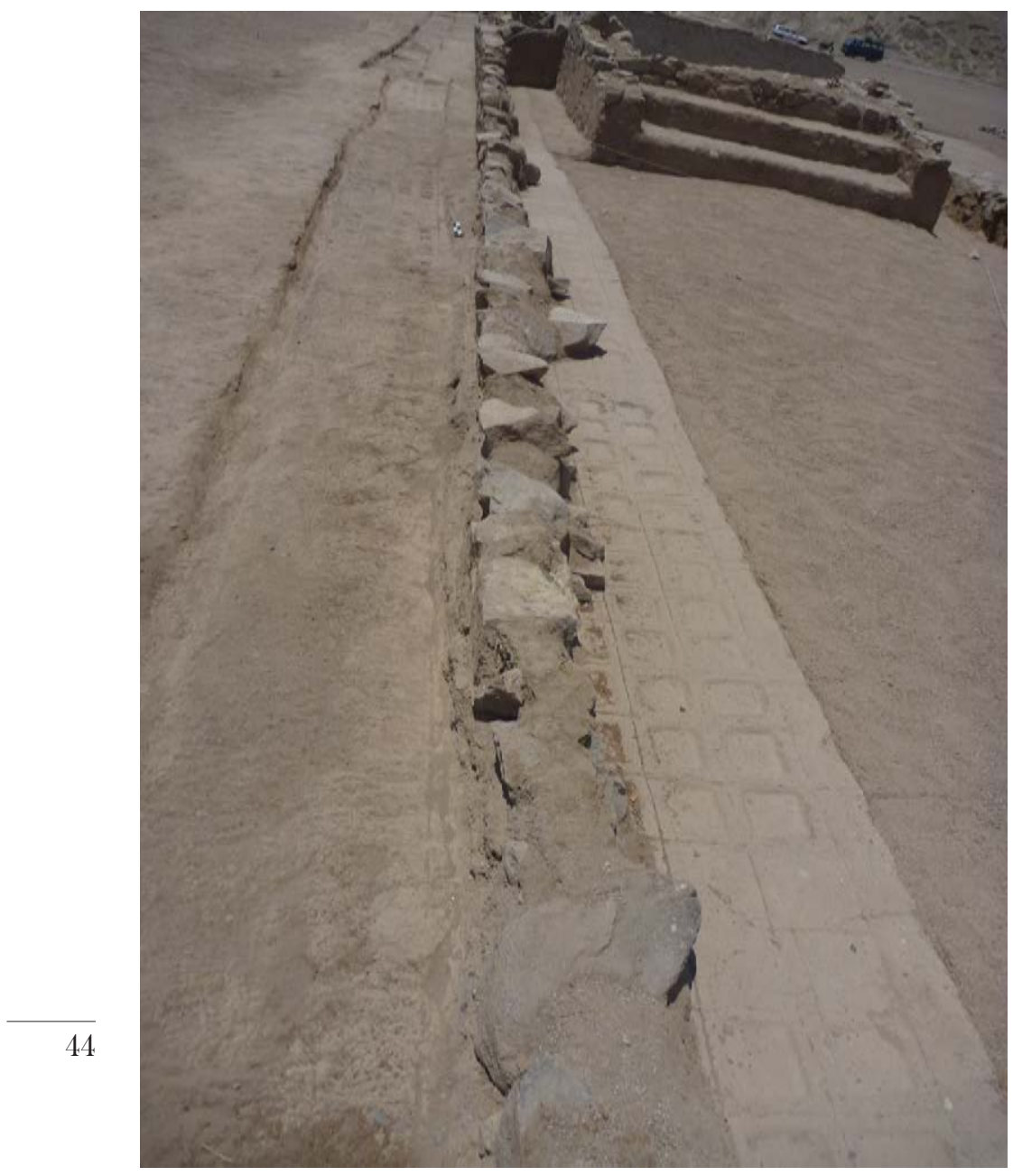

Figura 20 


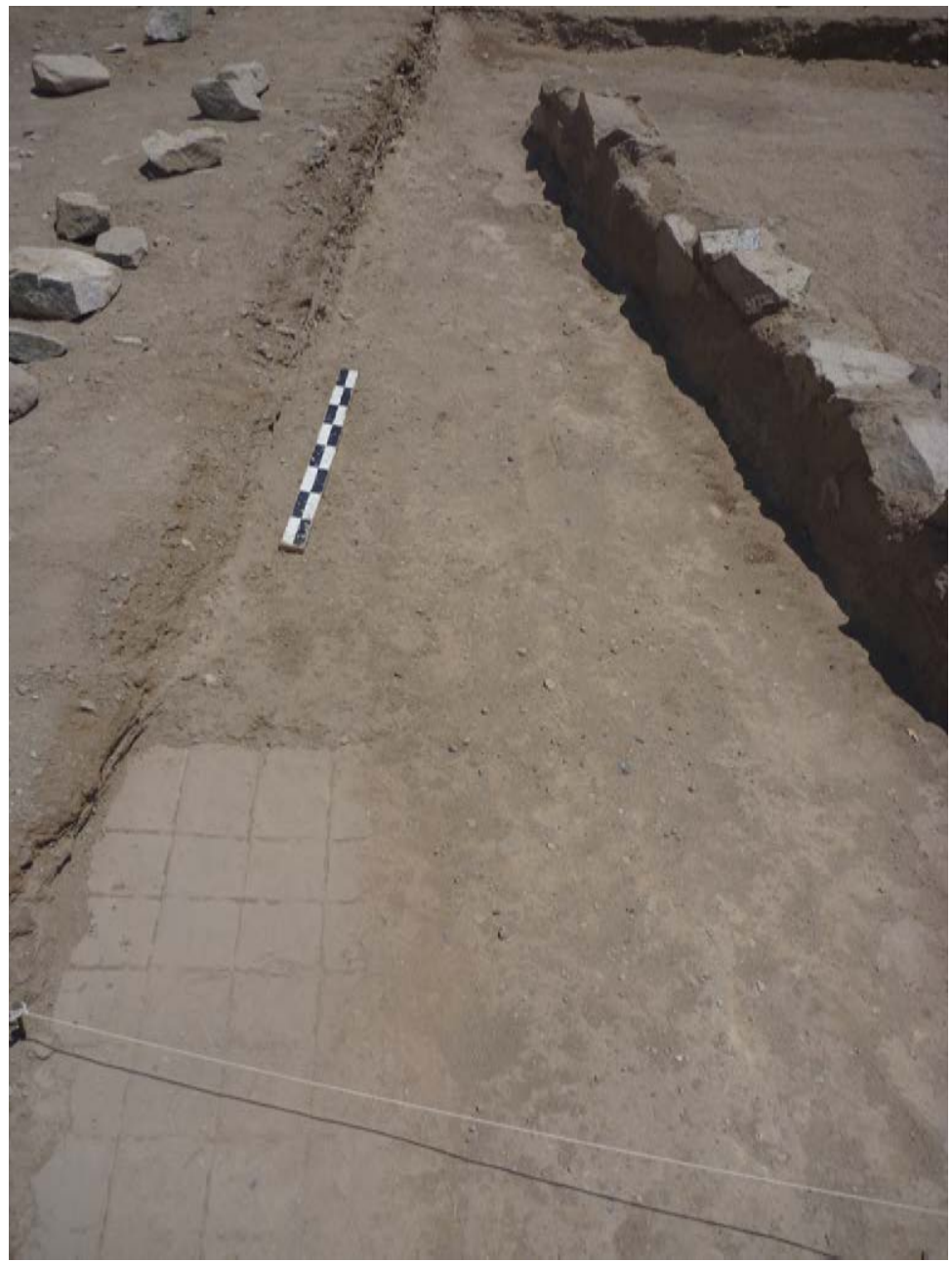

Figura 21 
Investigaciones en el ushnu mayor de Incahuasi, Cañete ...

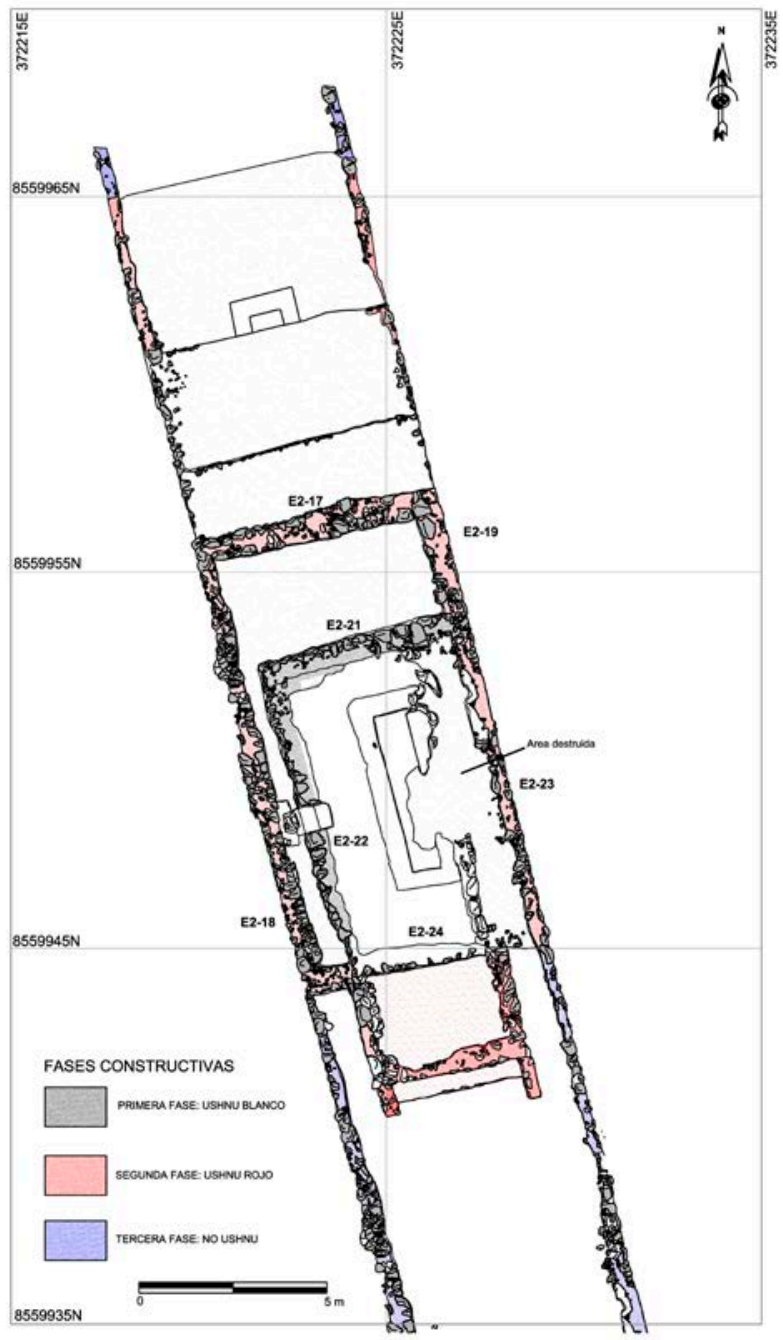

Figura 22 
Primera fase

Corresponde a la construcción de la plaza y a una plataforma de planta rectangular (figura 23) dispuesta sobre la plaza. El acceso a esta plataforma se realizaba por una escalera de cinco peldaños ubicada al lado oeste; sobre la plataforma se ubicó una pila rectangular orientada hacia el este. En su interior se encontraron evidencias de haber contenido cantos rodados pequeños. Toda esta estructura (incluida la cima) se encontraba pintada de color blanco, por lo que a esta fase la podemos denominar ushnu "blanco". Correspondería al inicio de la ocupación inca de Incahuasi, cuando el asentamiento era una base de operaciones militares. No está claro si las franjas elevadas con diseños en bajo relieve de forma cuadrangular a ambos lados del ushnu fueron construidas en esta fase.

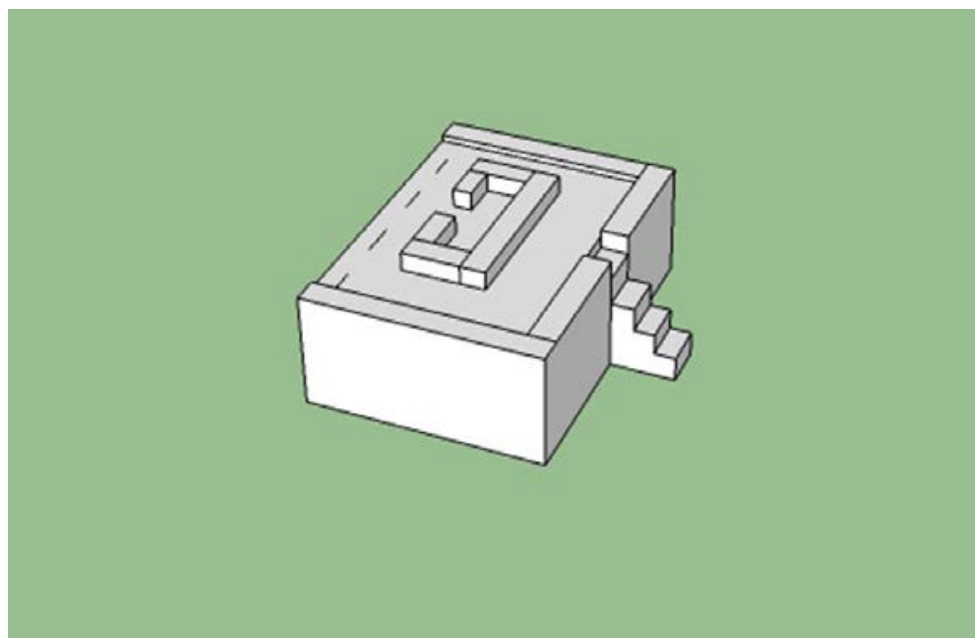

Figura 23 


\section{Segunda fase}

Aparentemente, en pleno proceso constructivo de la plataforma pintada de blanco hubo un cambio en el concepto de diseño de la estructura, pues se sellaron los muros blancos con muros de mayor tamaño que hicieron que la estructura adquiriera un volumen mayor. Así mismo, se cambió el acceso y se construyó una plataforma escalonada, la cual se adosó a su lado sur, lo que cambió no solo la forma sino la orientación de dicho acceso. El espacio entre los muros se rellenó con grava y cascajo limpio sin restos culturales, y se compactó. La cima de la plataforma se modificó, niveló y delimitó con muros de mayor nivel que la plataforma; toda esta estructura se pintó de un tono rojo claro, por lo que denominamos a esta fase ushnu "rojo" (figura 24).

Paralelamente, se construyeron dos plataformas que se adosaron al lado norte de la estructura y una pila de planta rectangular que se pintó de color amarillo. Esta pila reemplazaría a la anterior pila blanca cubierta en la cima de la plataforma, yendo más acorde con la nueva orientación de la estructura. En el interior de la nueva pila se hallaron cantos rodados pequeños. La asociación de las franjas elevadas con motivos cuadrangulares en bajo relieve a esta fase constructiva es clara.

\section{Tercera fase}

En la tercera fase, se modificó totalmente la función del usbnu, lo que estaría asociado a un gran cambio de función de todo el sector. En la estructura principal, este cambio se refleja en el sello de accesos y ampliaciones. Se sellaron tanto la escalera sur de acceso como la pila amarilla del lado norte, mediante la construcción de un camino elevado a modo de plataforma. Esta plataforma se proyecta hacia el lado sur y 
se conecta con la base de la escalera de acceso al palacio y al norte como un camino elevado que divide en dos a la plaza (figura 25). Es en esta fase que la plataforma dejó de utilizarse como ushnu y fue integrada al camino elevado que divide a la plaza y que comunica directamente con el frontis de la estructura principal del sector. Las franjas cuadriculadas en el lado oeste fueron cubiertas parcialmente por el muro del camino elevado.

Es interesante que las excavaciones no hayan encontrado evidencias de las dos escaleras de acceso compuestas de cinco peldaños que tanto Larrabure y Unanue y Harth-Terré mencionan en sus descripciones y planos del ushnu. La ausencia de estos elementos nos lleva a plantear dos hipótesis: que esta última fase del ushnu fue tan destruida por la ocupación moderna que no dejo ningún rastro en el registro arqueológico; o que corresponde a una ocupación postinca del ushnu y que fue construido (al igual que las modificaciones modernas) de manera superficial y que debido a esto la ocupación moderna lo desmontó fácilmente. La segunda hipótesis parece la más viable, tomando en consideración que las excavaciones han identificado la existencia de una ocupación postinca en el sector con estructuras de carácter doméstico adosadas a la estructura principal (el Palacio), y que HarthTerré menciona que el acceso al ushnu era realizado "por la parte anterior y posterior con dos escaleras de lajas de piedra asentadas sobre tierra" (Harth-Terré 1933: 107; el resaltado es mío). Como hemos visto, las escaleras de acceso asociadas directamente a la ocupación del ushnu corresponden a estructuras formales de barro y piedra. La única escalera asentada sobre la tierra corresponde al acceso moderno que encontramos antes de iniciar los trabajos. 
Investigaciones en el ushnu mayor de Incahuasi, Cañete ...

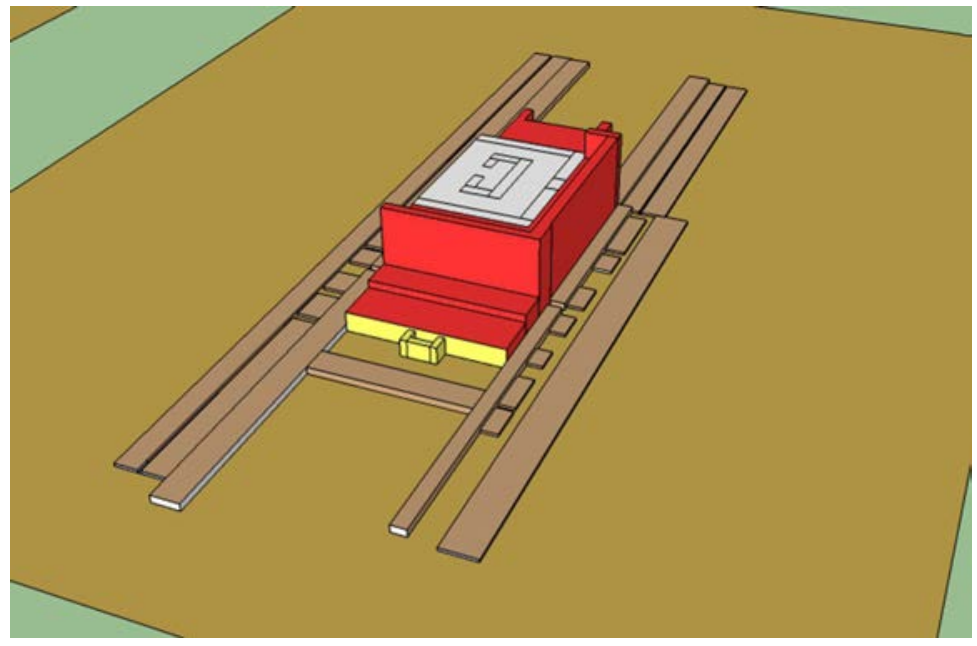

Figura 24

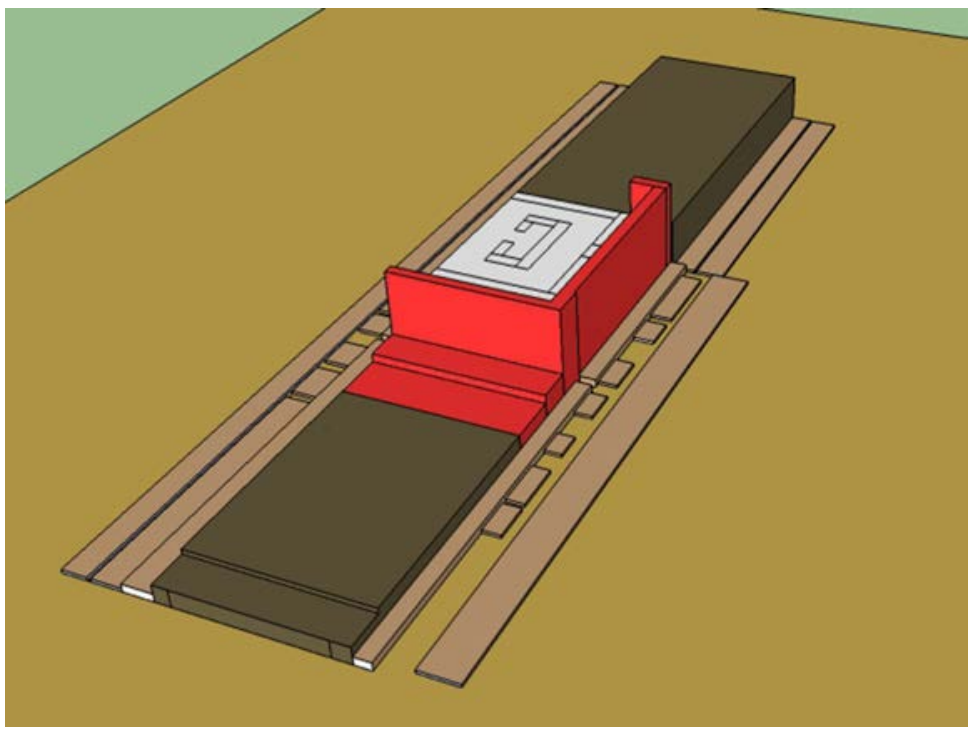

Figura 25 


\section{Agradecimientos}

Los trabajos de investigación en Incahuasi no se habrían llevado a cabo sin la tenacidad e interés de la licenciada Rosio Gonzales Díaz, del Gobierno Regional de Lima, quien en 3 meses logró que se corrigiera y aprobara un expediente técnico que estuvo estancado dos años. De igual manera, este proyecto no hubiera sido posible sin el apoyo del presidente regional de ese momento, el señor Javier Alvarado Gonzales del Valle. El Plan COPESCO Nacional y el Gobierno Regional de Lima financiaron los dos años de trabajos.

Durante estos dos años de trabajos, muchos arqueólogos pasaron por el proyecto, algunos memorables, otros no. Un agradecimiento a todos aquellos que llegaron hasta el final y le pusieron mucho empeño y entusiasmo a los trabajos: Daniel Dávila, jefe de campo, quien también realizó el análisis del material cerámico y su asistente Diana Carhuanina, quienes estuvieron a cargo de las excavaciones; Carlos Zapata, jefe del área de conservación de estructuras, y sus asistentes Lourdes Villa y Arlen Talaverano por concluir con los trabajos de conservación; Patricia Landa, conservadora de materiales; Claudia Molina, jefa de gabinete; Diana Mogrovejo por encargarse de los planos y su digitalización; Mary Ávila por su apoyo en la digitalización de planos de conservación y por revisar los restos de camélidos recuperados. Finalmente, un agradecimiento especial a los muchos practicantes que nos apoyaron con sus ganas de aprender, como Manuel Calongos, Boris Orccosupa, Diana Reynalte, Winnie Martínez, Karol Valenzuela, Víctor Hugo Condori, Andrea Gutiérrez, Cinthya Huarcaya, entre otros.

Recibido: 21 de julio del 2015

Aprobado: 20 de enero del 2016 


\section{Bibliografía}

CABELLO VALBOA, Miguel

1951 [1586] Miscelánea antártica. Una bistoria del Perú antiguo. Lima: Instituto de Etnología, Universidad Nacional Mayor de San Marcos.

CHU, Alejandro

En prensa "Incahuasi, Cañete: resultados preliminares de la temporada 2013". Manuscrito que se publicará en Actas del I Congreso Nacional de Arqueología. Lima: Ministerio de Cultura.

CIEZA DE LEÓN, Pedro de

1996 [1551] Crónica del Perú. Segunda parte. Edición de Francesca Cantú. Lima: Fondo Editorial de la Pontificia Universidad Católica del Perú, Academia Nacional de la Historia.

1995 [1553] Crónica del Perú. Primera parte. Edición de Franklin Pease García-Yrigoyen. Lima: Fondo Editorial de la Pontificia Universidad Católica del Perú, Academia Nacional de la Historia.

HARTH-TERRÉ, Emilio

1933 "Incahuasi. Ruinas incaicas del valle de Lunahuaná". Revista del Museo Nacional. Lima, volumen 2, número 2, pp. 99-125.

52 HYSLOP, John 1990

Inka settlement planning. Austin: University of Texas Press.

Inkawasi: The New Cuzco. Cañete, Lunabuaná, Peru. Oxford: Institute of Andean Research (New York). British Archaeological Reports (BAR), 174 p. (BAR International Series, 234). 
LARRABURE Y UNANUE, Eugenio

1935 [1893] Manuscritos y publicaciones. Volumen 2: Historia y arqueología, valle de Cañete. Lima: Imprenta Americana.

1904 Incashuasi. Ruinas de un edificio peruano del siglo XV. Lima: Tipografía de El Lucero.

LYNCH, Julieta; Marco Antonio GIOVANNETTTI y María Cecilia PÁEZ

2013 "Ushnus of the Inca provincial region: An analysis of two ceremonial platforms from Inca sites in Catamarca (Argentina)". Journal of Anthropological Archaeology. New York, 32, pp. 97-108.

MARCUS, Joyce

2008 Excavations at Cerro Azul, Peru: The architecture and pottery. Los Angeles: University of California, Cotsen Institute of Archaeology.

MATOS MENDIETA, Ramiro

1994 Pumpu. Centro administrativo inka de la puna de Junin. Lima: Editorial Horizonte.

MEDDENS, Frank

1997 "Function and meaning of the usnu in Late Horizon Peru”. Tawantinsuyu. Canberra, 3, pp. 4-14.

MEDDENS, Frank; Nicholas P. BRANCH, Cirilo VIVANCO POMACANCHARI, Naomi RIDDIFORD y Rob KEMP

2008 "High altitude ushnu platforms in the department of Ayacucho Peru, structure, ancestors and animating essence". En STALLER, John Edward (editor). Pre-Columbian Landscapes of Creation and Origin. Nueva York: Springer, pp. 315-356.

MONTEVERDE SOTIL, Luis Rodolfo

2010 "La configuración arquitectónica de los ushnus como 
espacios de libaciones y ofrendas líquidas durante el Tahuantinsuyo". Bulletin de l'Institut Français d'Études Andines. Lima, volumen 40, número 1, pp. 31-80.

2007 "Los ushnus y el culto a dioses con atributos sobre el agua en beneficio de las producción agrícola dentro de la administración Inca". Revista de Arqueológia Americana. México, D.F., 25, pp. 247-276.

MORRIS, Craig y Donald E. THOMPSON

1985 Huánuco Pampa. An Inca City and its Hinterland. London: Thames and Hudson.

OBERTI, Italo

1997 "Investigaciones preliminares en Usno-Moq'o, Abancay”. Tawantinsuyu. Canberra, 3, pp. 15-21.

PINO MATOS, José Luis

2010 "Yllapa usno: rituales de libación, culto a ancestros y la idea del ushnu en los Andes según los documentos coloniales de los siglos XVI-XVII". Arqueología y Sociedad. Lima, 12, pp. 77-108.

2005

"El ushnu y la organización espacial astronómica en la sierra central del Chinchaysuyu". Estudios Atacameños. San Pedro de Atacama, 29, pp. 143-161.

2004 "El Ushnu Inca y la organización del espacio en los principales Tampus de los Wamani de la sierra central del Chinchaysuyu". Chungara. Revista de Antropología Chilena. Arica, volumen 36, número 2, pp. 303311.

PRESBÍTERO RODRÍGUEZ, Gonzalo; Maciej SOBEZYK y Janusz WOLOSZYN

2000-2001 "Plataforma ceremonial con ushnu del sitio Maucallacta". Andes. Boletín de la Misión Arqueológica Andina. Varsovia, 3, pp. 185-199. 
RAFFINO, Rodolfo; Diego GOBBO; Rolando VÁZQUEZ; Aylen CAPPARELLI; Victoria MONTES; Rubén ITTURRIZA, Cecilia DESCHAMPS y Marcelo MANNASERO

1997 "El ushnu de El Shincal del Quimivil". Tawantinsuyu. Canberra, 3, pp. 22-39.

RIVAS OTAIZA, Cora

2011 "Inkahuasi: poder y transformación de un centro político-militar a un centro administrativo inca". En LANE, Kevin y Milton LUJÁN (editores). Arquitectura prehispánica tardia: construcción y poder en los Andes centrales. Lima: Fondo Editorial Universidad Católica Sedes Sapientiae, pp. 385-426.

ROSTWOROWSKI de Diez Canseco, María

1978-1980 “Guarco y Lunahuaná. Dos señoríos prehispánicos de la costa sur central del Perú". Revista del Museo Nacional. Lima, 44, pp. 153-214.

RUIZ DE ARCE, Juan

1968 [1545] "La "Advertencia" de Juan Ruiz de Arce o Alburquerque (hacia 1545)". En Biblioteca Peruana. El Perú a través de los siglos, Primera Serie. Lima: Editores Técnicos Asociados, tomo I, pp. 405-438.

SANCHO DE LA HOZ, Pedro

1968 [1534] "Relación para su Majestad". En Biblioteca Peruana. El Perú a través de los siglos, Primera Serie. Lima: Editores Técnicos Asociados, tomo I, pp. 275-344.

SANTO TOMÁS, Domingo de

2013 [1560] Lexicon o Vocabulario de la lengua general del Perú. Edición crítica de Julio Calvo Pérez y Henrique Urbano. Tomo II. Lima: Fondo Editorial de la Universidad San Martín de Porres.

1951 [1560] Lexicon o vocabulario de la lengua general del Perú. Edición facsimilar, Lima: Universidad Nacional Mayor de San Marcos, Instituto de Historia. 
STRONG, William D. y Gordon R. WILLEY

1943 The Southern Survey. Archaeological Studies in Peru, 19411942. Nueva York: Columbia University Press, pp. 18-25 (Columbia Studies in Archaeology and Ethnology, 1).

URTON, Gary y Alejandro CHU

En prensa "The Inkawasi khipu archive: an Inka state storage facility and accounting center on the south coast of Peru". Se publicará en Latin American Antiquity.

VILLAR CÓRDOVA, Pedro

1982 [1935] Las culturas prehispánicas del departamento de Lima. Edición facsimilar. Lima: Ediciones Atusparia.

WILLIAMS LEÓN, Carlos y Manuel MERINO JIMÉNEZ 1974 Inventario, catastro y delimitación del patrimonio arqueológico del valle de Cañete. 2 volúmenes. Lima: Instituto Nacional de Cultura, Centro de investigación y Restauración de Bienes Monumentales.

WOEOSZYN, Janusz Z.; Maciej SOBCZYK; Gonzalo PRESBÍTERO RODRÍGUEZ y Paweł BUDA

2010 "Espacios ceremoniales del sitio inca de Maucallacta (Departamento de Arequipa, Perú)". Dialogo Andino. Arica, 35, pp. 13-23.

ZUIDEMA, R. Tom

1989 [1980] “El ushnu”. En BURGA, Manuel (compilador). Reyes y guerreros. Ensayos de cultura andina. Lima: Asociación Peruana para el Fomento de las Ciencias Sociales (FOMCIENCIAS), pp. 402-454. 